\title{
"My Questionnaire is Too Long!" The assessments of motivational-affective constructs with three-item and single-item measures
}

\author{
Katarzyna Gogol ${ }^{\mathrm{a}, \mathrm{b}, *}$, Martin Brunner ${ }^{\mathrm{a}, \mathrm{c}}$, Thomas Goetz ${ }^{\mathrm{d}, \mathrm{e}}$, Romain Martin ${ }^{\mathrm{b}}$, Sonja Ugen ${ }^{\mathrm{b}}$, Ulrich Keller $^{\mathrm{b}}$, \\ Antoine Fischbach ${ }^{\mathrm{b}}$, Franzis Preckel ${ }^{\mathrm{f}}$ \\ ${ }^{a}$ Free University of Berlin, Berlin, Germany \\ ${ }^{\mathrm{b}}$ University of Luxembourg, Luxembourg, Luxembourg \\ ${ }^{\mathrm{c}}$ Berlin-Brandenburg Institute for School Quality, Berlin, Germany \\ d University of Konstanz, Konstanz, Germany \\ e Thurgau University of Teacher Education, Kreuzlingen, Switzerland \\ ${ }^{\mathrm{f}}$ University of Trier, Trier, Germany
}

Keywords:

Academic self-concept

Academic anxiety

Short scale

Single-item measure

Psychological assessment

\begin{abstract}
A B S T R A C T
Because testing time in educational research is typically scarce, the use of long scales to assess motivational affective constructs can be problematic. The goal of the present study was to scrutinize the psychometric properties of short scales (with three items) and single item measures for two core motivational affective constructs (i.e., academic anxiety and academic self concept) by conducting sys tematic comparisons with corresponding long scales across school subjects and within different subject domains (i.e., mathematics, German, French). Statistical analyses were based on representative data from 3879 ninth grade students. All short forms possessed satisfactory levels of reliability (range: .75 .89) and substantial correlations with the long scales (range: .88 .97); correlational patterns with educational stu dent characteristics (e.g., achievement, school satisfaction, gender, academic track, and socioeconomic status) were comparable to those obtained with the corresponding long scales (all average differences in correlations below .07). The correlational patterns between all single item measures and the external criteria were similar to those obtained with the corresponding long scales (all average differences in correlations below .08), yet the single item measures demonstrated low to modest score reliabilities (estimated with the model based omega coefficient; range: .22 .72) and correlations with full scales (range: .50 .88). When long scales are not applicable, short forms and perhaps even single item measures may represent psychometrically sound alternatives for assessing academic anxiety and academic self concept for educational research purposes.
\end{abstract}

\section{Introduction}

Student learning is a complex process that can be understood only by investigating multiple constructs, for example, learning related feelings and motivational factors as vital variables that affect students' cognition, learning, and performance (Linnenbrink \& Pintrich, 2000). To obtain comprehensive insights into students' learning related affect and motivation, it is necessary to assess multiple motivational affective constructs and to analyze their multivariate relations. However, in educational research, testing time is typically scarce, particularly in large scale assessment

* Corresponding author. Free University of Berlin, Department of Education and Psychology, Habelschwerdter Allee 45, 14195 Berlin, Germany.

E-mail address: katarzyna.gogol@fu-berlin.de (K. Gogol). studies, in longitudinal studies with a measurement burst design, or in studies that use experience sampling as an ambulatory form of assessment. Although such study designs provide important insights into students' learning by including representative student populations or by providing information about intraindividual variability in ecologically valid settings, the very nature of such studies renders the assessment of many constructs with measures that include numerous items problematic, and in most cases, even impossible. The purpose of the present study was therefore to scrutinize the practice of using very short scales or even a single item to assess core motivational affective constructs. To this end, we studied the psychometric properties of short scales (consisting of three items) and single item measures for two constructs: academic anxiety and academic self concept. Both constructs rep resent key motivational affective student characteristics that have 
a long tradition in educational science. Academic anxiety and aca demic self concept are not only important with respect to students' learning, but are also considered to be vital learning outcomes themselves (e.g., Goetz, Cronjaeger, Frenzel, Lüdtke, \& Hall, 2010; Marsh \& O‘Mara, 2008; Marsh, Trautwein, Lüdtke, Koller, \& Baumert, 2005; Marsh \& Yeung, 1997; Zeidner, 1998).

\subsection{Academic anxiety and academic self concept: Definitions and relations to important student characteristics}

\subsubsection{Academic anxiety}

Academic anxiety refers to feelings of worry, nervousness, and uneasiness in achievement related situations in the school context. Early research on academic anxiety conceived of it as a single, uni dimensional, and domain transcending construct (e.g., Mandler \& Sarason, 1952). This proposition has been extended in several important ways: First, two key aspects of anxiety have been further differentiated: worry and emotionality (Liebert \& Morris, 1967; Zeidner, 2007; for an alternative conceptualization of anxiety, see e.g., Scherer, 1984). The worry facet represents a cognitive compo nent that refers to thoughts about one's performance and the expected consequences of failure. The emotionality facet repre sents an affective physiological component that refers to the affec tive experience of anxiety and perceived physical arousal in related situations (Goetz, Preckel, Zeidner, \& Schleyer, 2008; Hembree, 1988; Zeidner, 2007). Importantly, although the two facets are empirically distinct (Zeidner, 2007), they are highly correlated, which points to a substantial amount of common variance that may be attributed to a general factor representing the general level of anxiety. For example, Hembree (1988) reported a correlation of $r=.78$ between worry and emotionality in his meta analysis. Sec ond, in more recent educational research (dating back across the last 1015 years), academic anxiety has been considered to be highly specific to subject domains (Goetz, Frenzel, Pekrun, Hall, \& Lüdtke, 2007) or to typical educational settings, such as the expe rience of anxiety during exams (test anxiety) or lessons at school (class anxiety).

To integrate these different conceptualizations of academic anxiety, it may be best to consider academic anxiety to be hierar chically organized where a general construct operates at the apex of the hierarchy and more specific facets (e.g., worry and emotion ality as experienced in various educational settings) constitute lower hierarchical levels (see Pekrun, Goetz, Frenzel, Barchfeld, \& Perry, 2011). Further, this hierarchical conceptualization may be applied to understand students' experiences of anxiety across school subjects (i.e., academic anxiety is conceived to be a domain general construct) or within a certain school subject. The distinction between domain general and domain specific concep tions of academic anxiety is particularly important when it comes to studying the relations between academic anxiety and other stu dent characteristics. More specifically, the specificity matching principle (e.g., Swann, Chang Schneider, \& McClarty, 2007; see also Wittmann, 1988) predicts that general predictor variables (e.g., domain general academic anxiety) will be most strongly related to general outcomes (e.g., general academic achievement), whereas more specific predictor variables (e.g., mathematics anxiety) will be more strongly related to (corresponding) specific outcomes (e.g., mathematics achievement). Finally, reports of academic anx iety may refer to the dispositional trait level or to the momentary state of anxiety (cf. Goetz, Bieg, Lüdtke, Pekrun, \& Hall, 2013). In the present paper, we focused on the trait level.

A rich body of knowledge is available with regard to the relations between academic anxiety and other important student character istics. There is strong empirical evidence that indicates negative associations between academic anxiety and academic performance (Hembree, 1988, 1990; Lee, 2009; Ma, 1999; Zeidner, 1998). Results from meta analyses and selected studies with representative stu dent samples from large scale assessment studies are presented in Table 1. Negative relations have also been documented for socio affective variables such as subjective well being and psycho logical health (Diener, 2000). With respect to differences related to specific groups, in his meta analysis, Hembree (1988) found that girls reported higher levels of test anxiety than boys in general (similar results are reported for test anxiety in mathematics; Hembree, 1990) and that students with high socioeconomic status (SES) scored consistently lower on test anxiety than students with low SES (with an average correlation of $r=-.13$ ).

\subsubsection{Academic self concept}

Academic self concepts are mental representations of one's abilities in academic subjects (Brunner et al., 2010) that entail aspects of both self description and self evaluation (Brunner, Keller, Hornung, Reichert, \& Martin, 2009; Marsh \& Craven, 1997). Notably, current models of academic self concept such as the Marsh/Shavelson Model (Marsh, 1990a) or the nested Marsh/ Shavelson model (Brunner et al., 2010) conceive of the academic self concept as a multidimensional construct with separate com ponents for specific school subjects and a domain general aca demic self concept. Domain specific academic self concepts reflect an individual's impression of his or her ability in a specific academic domain, such as mathematics ("I am good at mathemat ics") or German ("I am good at German"), whereas the domain general academic self concept reflects an individual's evaluation of his or her academic abilities across subjects ("I am good at most school subjects").

Positive academic self concepts are beneficial for many psycho logical and behavioral outcomes such as academic emotions (Goetz, Frenzel, Hall, \& Pekrun, 2008), subsequent academic effort (Trautwein, Lüdtke, Schnyder, \& Niggli, 2006), and success (Helmke \& van Aken, 1995; Marsh \& Yeung, 1997; Trautwein, Lüdtke, Marsh, Köller, \& Baumert, 2006; Valentine, DuBois, \& Cooper, 2004). The correlations between academic self concepts and indicators of academic abilities (e.g., grades, standardized achievement tests) as typically found in empirical studies are pre sented in Table 1. Moreover, students' school satisfaction was found to be positively associated with their academic self concepts (e.g., $r=.45$ in general, $r=.39$ for mathematics, and $r=.31$ for reading; Huebner, 1994). Regarding gender differences in academic self con cepts, the results have been inconclusive. Many studies have indi cated no significant differences in the general academic self concept (Brunner et al., 2009; Hergovich, Sirsch, \& Felinger, 2004; Marsh, Smith, \& Barnes, 1985; Skaalvik \& Rankin, 1990), a higher self concept in mathematics for boys, and a higher verbal self con cept for girls (Brunner et al., 2009; Hattie, 1992; Hergovich et al., 2004; Jackson, Hodge, \& Ingram, 1994; Marsh, Smith et al., 1985; Preckel, Goetz, Pekrun, \& Kleine, 2008; Skaalvik \& Rankin, 1990). However, other studies have challenged these results by document ing a higher general academic self concept for males (e.g., Chiam, 1987; Jackson et al., 1994), a higher general academic self concept for females (e.g., Lau, Siu, \& Chik, 1998), and no significant gender differences in mathematics self concept (e.g., Ma \& Kishor, 1997; Marsh, 1989; Marsh \& Yeung, 1998). Furthermore, a positive relation has been found between socioeconomic status and academic self concept (Marsh, 1987; Marsh \& Parker, 1984), and children in higher academic tracks have been found to have slightly higher academic self concepts than children who attend lower tracks (Marsh, 1987; Marsh, Kong, \& Hau, 2000).

\subsection{Measurement of academic anxiety and academic self concept}

Academic anxieties and academic self concepts are not directly observable but are rather latent constructs. Thus, to assess 
Table 1

Mean correlations between student achievement with academic anxiety and academic self-concept as obtained in meta-analyses and large-scale assessment studies with representative student samples.

\begin{tabular}{|c|c|c|c|}
\hline & General academic achievement & Mathematics achievement & Verbal achievement \\
\hline \multicolumn{4}{|l|}{ Anxiety } \\
\hline General academic test anxiety & $\begin{aligned} r & =-.29(\mathrm{M} ; N=6390)^{\mathrm{a}} \\
r & =-.23(\mathrm{M} ; N=28,424)^{\mathrm{b}}\end{aligned}$ & $r=-.22(\mathrm{M} ; N=6534)^{\mathrm{a}}$ & $r=-.24(\mathrm{M} ; N=10,761)^{\mathrm{a}}$ \\
\hline Mathematics anxiety & & $\begin{array}{l}r=-.34(\mathrm{M} ; N=5555)^{\mathrm{c}} \\
r=-.27(\mathrm{M} ; N=18,279)^{\mathrm{d}}\end{array}$ & $r=-.06(\mathrm{M} ; N=1941)^{\mathrm{c}}$ \\
\hline \multicolumn{4}{|l|}{ Self-concept } \\
\hline General academic self-concept & $\begin{array}{l}r=.34(\mathrm{M} ; N=46,482)^{\mathrm{f}} \\
r=.29(\mathrm{~L} ; N \quad 106,680)^{\mathrm{e}}\end{array}$ & $r=.24(\mathrm{~L} ; N=106,680)^{\mathrm{e}}$ & $r=.28(\mathrm{~L} ; N=106,680)^{\mathrm{e}}$ \\
\hline Mathematics self-concept & $r=.21(\mathrm{~L} ; N \quad 106,680)^{\mathrm{e}}$ & $\begin{array}{l}r=.20(\mathrm{M} ; N=30,317)^{\mathrm{f}} \\
r=.43(\mathrm{M} ; N=125,308)^{\mathrm{g}} \\
r=.26(\mathrm{~L} ; N=106,680)^{\mathrm{e}}\end{array}$ & $\begin{array}{l}r=.14(\mathrm{M} ; N=125,308)^{\mathrm{g}} \\
r=.13(\mathrm{~L} ; N=106,680)^{\mathrm{e}}\end{array}$ \\
\hline Verbal self-concept & $r=.19(\mathrm{~L} ; N \quad 106,680)^{\mathrm{e}}$ & $\begin{array}{l}r=.12(\mathrm{M} ; N=125,308)^{\mathrm{g}} \\
r=.10(\mathrm{~L} ; N=106,680)^{\mathrm{e}}\end{array}$ & $\begin{array}{l}r=.20(\mathrm{M} ; N=3669)^{\mathrm{f}} \\
r=.35(\mathrm{M} ; N=125,308)^{\mathrm{g}} \\
r=.24(\mathrm{~L} ; N=106,680)^{\mathrm{e}}\end{array}$ \\
\hline
\end{tabular}

Note. $\mathrm{M}=$ meta-analysis; $\mathrm{L}=$ large-scale assessment study. The second number in brackets indicates the sample size on which the correlation estimate was based.

a Hembree (1988).

b Seipp (1991).

c Hembree (1990).

d Ma (1999).

e Brunner et al. (2009).

f Hansford and Hattie (1982).

g Möller, Pohlmann, Köller, and Marsh (2009).

students' levels on these constructs, observable (manifest) mea sures are necessary. Self report questionnaires are by far the most prevalent method for assessing motivational affective constructs such as academic anxieties and academic self concepts. According to Zeidner $(1998,2007)$, self reports are also probably the best method because directly asking a person for a self assessment pro vides the most direct access to his/her subjective thinking and feel ing. When participants' experiential states and thinking are of interest, asking the person may even be the only choice of assess ment method (Baumeister, Vohs, \& Funder, 2007). Additionally, self reports possess good psychometric properties and are rela tively simple to administer (Zeidner, 2007).

In general, text books on measurement recommend using mul tiple items to represent psychological constructs (e.g., Nunally, 1978). For academic anxieties and academic self concepts, there exist several well established multiple item scales; for example, the anxiety scale from the Achievement Emotions Questionnaire (Pekrun et al., 2011) with a total of 24 items for class and test related anxieties and the Academic Self Description Questionnaire ASDQ for school related self concepts (Marsh, 1990a), containing six items per school domain. However, on many occasions, researchers need more economical measures.

\subsection{Advantages and disadvantages of short scales and multiple item measures}

The debate about the development of short scales has a long history with many criticisms expressed about this approach (e.g., Levy, 1968; Loo, 2002) or the way this approach has been used (e.g., Smith, McCarthy, \& Anderson, 2000). In the following, the advantages and disadvantages of short scales and multiple item measures will be contrasted with regard to both practical and psy chometric issues.

To study the complexities of student learning, questionnaires in educational research aim to assess not only a single but rather many constructs. Yet, in doing so, researchers face practical con straints (Donnellan, Oswald, Baird, \& Lucas, 2006), involving a lim ited amount of time allowed for testing, restricted space on a single page of the questionnaire (which may be necessary when all con struct indicators need to be printed on one page), or financial lim itations (to account for the costs of additional pages in a questionnaire or the costs of translation). From this practical point of view, short measures seem especially compelling as they reduce not only research costs but also survey length (Hoeppner, Kelly, Urbanoski, \& Slaymaker, 2011).

However, short scales and especially single item measures are assumed to have psychometric disadvantages. First, in comparison to long inventories, short scales and single item measures in par ticular are presumed to demonstrate poor score reliabilities by being more vulnerable to random measurement errors. Referring to a proposition in classical test theory, the proportion of measure ment error in the total scale score is supposed to decrease as ran dom measurement errors cancel each other out when they are averaged across multiple items (Credé, Harms, Niehorster, \& Gaye Valentine, 2012). By this logic, longer scales should demon strate more acceptable levels for estimates of internal consistency.

Second, long scales are thought to have better criterion related validity than short scales. This claim is based on (a) the argument that error variance is reduced on long scales and (b) another clas sical test theory assumption that states that the correlation between a test and another construct cannot exceed the reliability of the test (Lord \& Novick, 1968).

Third, multiple item measures are considered to be superior to single item measures concerning their content validity. Specifi cally, long scale scores may represent all facets that constitute the construct, whereas the assessment of a construct with a single item makes it impossible to differentiate between subfacets of a construct (Jordan \& Turner, 2008). For example, the administration of a single item to assess mathematics anxiety would not allow a researcher to test distinct effects of the worry and emotionality components or of the motivational versus cognitive components of academic anxiety on academic outcomes (Hembree, 1988).

It should also be noted that short scales have technical limita tions concerning latent variable modeling because a minimum of at least three indicators per factor are needed for a one factor model to be identified without making very strong assumptions concerning the psychometric properties of these indicators (Kline, 2010). Moreover, many statistical procedures require con tinuous raw data that are normally distributed. However, for single items with a limited number of response categories, the assump tion of continuous normally distributed data may not be tenable. Notably, even when single items contain only four response 
categories, traditional statistical methods can yield trustworthy and unbiased results (see Rhemtulla, Brosseau Liard, \& Savalei, 2012). In other circumstances, more sophisticated methods that best fit the distributional properties of the measures under inves tigation should be chosen (see, e.g., the methods discussed by Rhemtulla et al. (2012) or Wirth and Edwards (2007)).

On the other hand, multiple item measures often include similar and redundant items, which can be problematic for various reasons. The proposition of the higher reliability of long scales is, for exam ple, valid only under the assumption that errors are random. Com mon method variance due to similarly worded items or other compounded systematic errors produced by redundant items (e.g., because of socially desirable responding; Robins, Hendin, \& Trzesniewski, 2001) can lead to artificially high reliability estimates (Yang \& Green, 2011). Moreover, perceived item redundancy on long scales can be interpreted as an indicator of low face validity by the respondents (Christophersen \& Konradt, 2011) and result in lower motivation (Nevo, 1985). Thus, monotonous and time consuming long scales may have a negative influence on the respondents (Gardner, Cummings, Dunham, \& Pierce, 1998). They may lead participants to experience boredom, irritation, fatigue, annoyance, frustration, or resentment (Robins et al., 2001; Wanous, Reichers, \& Hudy, 1997), and might result in lower cogni tive participation (Stanton, Sinar, Balzer, \& Smith, 2002). Such circumstances can give rise to random and careless responding, which in turn may affect the reliability and the validity of the results (Credé et al., 2012; McCrae, Kurtz, Yamagata, \& Terracciano 2011).

Furthermore, people are more likely to participate in a study when it demands less time (Konstabel, Lönnqvist, Walkowitz, Konstabel, \& Verkasalo, 2012). As the willingness to participate decreases as the number of items increases (Bean \& Roszkowski, 1995), long questionnaires may lead respondents to skip questions, refuse to complete a questionnaire, refuse to participate in future studies, or to drop out of longitudinal studies (Donnellan et al., 2006). The resulting missing data can potentially threaten the reli ability and validity of the measurement (McKnight, McKnight, Sidani, \& Figueredo, 2007). Additionally, lower response rates and attrition may be associated with sampling bias (Moore, Halle, Vandivere, \& Mariner, 2002) because only the most involved and interested or least busy participants may be the ones to answer all questions or decide to participate in a study further (Moore et al., 2002). Such sampling bias undermines the generalizability of the results (i.e., external validity; McKnight et al., 2007). Thus, especially when multiple constructs need to be assessed and the above mentioned problems associated with long scales accumu late, short scales may provide a useful alternative.

There are also advantages specific to single item measures with regard to interpretability. For example, the interpretation of summed or averaged scale scores is difficult because after such transformations of the item scores, the correspondence to the response categories vanishes. Therefore, for communicating the results of a test to a broad audience (with little expertise in psycho metrics), it may be better to use more intuitive measures such as single items for which the value (e.g., 1) can be assigned to an eas ily understandable meaning (e.g., "do not agree"). Note that previ ous research has shown that when constructs are unambiguous and clear to the respondents, single items may provide meaningful information (Ainley \& Patrick, 2006). Example constructs are mood and pain (e.g., McCormack, Horne, \& Sheather, 1988) in medical research or global job satisfaction in the field of industrial and organizational psychology (e.g., Wanous et al., 1997). When con structs are complex, single items may even be superior to long scales that comprised of different facets (Nagy, 2002; Scarpello \& Campbell, 1983; Wanous et al., 1997). Specifically, long scales can result in misleading assessments as some facets may be eval uated as not relevant by some respondents even though all facets are equally weighted for all respondents on long scales. Thus, the advantage of single items is that when individuals respond to a general single item, their response may reflect only those facets that are important to them individually.

Taken together, shortening the long form of a scale may result in solving a number of the above mentioned problems that are associated with the application of multiple items while simulta neously providing the specific advantages of short scales. However, the shorter the scale, the more difficult it becomes to guarantee its psychometric qualities, with single items having the greatest potential to be problematic.

\subsection{Empirical evidence}

Studies that have tested the psychometric qualities of short forms or single item measures have shown mixed empirical results. Despite the shortcomings mentioned above, many studies have documented that even single items can show sound psycho metric properties comparable to those of longer scales and can therefore provide an acceptable balance between practical needs and psychometric concerns in various areas. Examples are the short form and single item assessments of job satisfaction (Nagy, 2002; Wanous et al., 1997), personality traits (e.g., Gosling, Rentfrow, \& Swann, 2003; Rammstedt \& John, 2007), well being and life satisfaction (Diener, 1984; Lucas \& Donnellan, 2012), self esteem (Robins et al., 2001), and self efficacy (Hoeppner et al., 2011).

However, there exists relatively little research that has system atically evaluated the psychometric qualities of short forms (and of single item measures in particular) that measure motivational affective constructs. Whereas short scales (with three items) and single item measures have sometimes been used to assess aca demic anxieties and academic self concepts (e.g., PISA study 2000, German extension to the year 2003 cycle of PISA; Brunner et al., 2010; Goetz, Frenzel, Stoeger, \& Hall, 2010; Goetz, Preckel, Pekrun, \& Hall, 2007; Gottfried, 1982; Nett, Goetz, \& Hall, 2011; Niepel, Brunner, \& Preckel, 2014; Preckel and Brüll, 2008; Stipek \& Mason, 1987; Trautwein, Lüdtke, Marsh et al., 2006), to the best of our knowledge, almost no studies have systematically compared the reliabilities and different forms of validity estimations of such short scales (consisting of three items) and single item measures to those of corresponding longer scales. An exception is the study by Marsh, Barnes, and Hocevar (1985), which compared a multi ple item measure (SDQ) of self concepts to single summary items for each self concept domain and concluded that the multiple item scales had better psychometric qualities than the single items. However, Marsh (1986) suggested that it is better to use the single items to measure the specific self concept dimensions than not to assess multiple dimensions of this construct at all. For anxiety (and other school related emotions), Goetz (2004) found that single item measures show acceptable reliability and validity (see also Goetz et al., 2007). Notably, none of these studies investigated and compared the relations between the single item measures and other important student characteristics to those same rela tions obtained with corresponding longer scales that is, no study has assessed the nomological network with single item measures or short scales as compared to the corresponding long scales.

\subsection{The present study}

Although the conventional wisdom on measurement recom mends using long scales, in various research areas in psychology, short scales or even single item measures have been found to show acceptable psychometric properties that were comparable or equal to those of multiple item measures. However, little knowledge has been obtained thus far with regard to the potential to assess moti 
vational affective constructs by means of short scales and single item measures as alternatives to long questionnaires. Therefore, the present study investigated the feasibility of three item scales and single items using two important constructs from the motiva tional affective domain as examples: academic anxiety and aca demic self concept. Specifically, we thoroughly evaluated the psychometric properties of three item scales and single item mea sures of domain general and domain specific (i.e., mathematics, German, French) academic anxiety and academic self concept by systematically comparing them with their corresponding long scales. The analyses were applied to a large and representative stu dent sample. Specifically, the psychometric qualities were evalu ated with respect to several vital measurement questions (see Table 2): (a) How reliable are short scales and single item mea sures? (b) How well do short scales and single item measures reproduce the information obtained by long scales? (c) How well do short scales and single item measures reproduce the relations in the nomological network obtained by long scales? The nomolog ical network that we investigated in the present study included student characteristics that were measured by methods other than self reports and/or for which a rich body of knowledge has been accumulated on their relations to academic anxieties and academic self concepts, involving student achievement, school satisfaction, gender, socioeconomic status, and academic track.

\section{Method}

\subsection{Sample}

The analyses of the present study were based on representative data from 3879 students (1901 females) who participated in the 2011 cycle of the Luxembourg school monitoring program (Martin \& Brunner, 2012) at the beginning of the ninth grade (about 59\% of all ninth grade students in Luxembourg). The main aim of this program was to evaluate key educational outcomes (e.g., domain specific achievement and students' motivational affective characteristics). In the Luxembourg school system, after the sixth grade, students are assigned to different secondary tracks as a result of achievement based selection. These secondary tracks differ in mean achievement levels as well as in the subjects taught. On the administrative level, two main secondary strands can be distinguished in Luxembourg. In the present study 2546 students (65.6\%) attended the lower academic track, and 1333 students (34.4\%) attended the upper academic track. Students could choose the language (German vs. French) for items measuring academic anxieties and academic self concepts. In the present study, we analyzed data from the students who responded to the academic anxiety and academic self concept scales in German.

\subsection{Measures}

In the 2011 cycle of the Luxembourg school monitoring program, all achievement tests and questionnaires were computerized. The students' questionnaires were administrated in a multi matrix design in which six booklets covering different assessment domains were randomly assigned to the students because the application of all scales to all students was not possible due to practical limitations. Table A1 in Appendix A shows how the scales were distributed across the booklets and the numbers of stu dents who responded to each scale. Specifically, one sixth of the students responded to the following questionnaires, respectively: domain general academic anxiety, mathematics anxiety, German anxiety, French anxiety, French self concept, as well as mathemat ics self concept, German self concept, and the domain general aca demic self concept. As a consequence of this research design, the psychometric properties of the respective scales were evaluated based on the data from about one sixth of the sample size (see Table 6).

\subsubsection{Academic anxiety and academic self concept scales}

The academic anxiety as well as the academic self concept instrument administered in the 2011 cycle of the Luxembourg school monitoring program covered three core school subjects (i.e., mathematics, German, and French) as well as domain general academic anxiety and the domain general academic self concept. In line with other large scale assessments (Marsh et al., 2006), stu dents responded to each item on a rating scale with four catego ries: disagree, disagree somewhat, agree somewhat, and agree. Each construct was assessed with a full scale from which scores of three items constituting a three item measure and single items were extracted. In the following, the three item measures will be referred to as the short form.

2.2.1.1. Academic anxiety. Full scale (FS). A new 17 item scale was developed by the authors of the present study. The new scale was based on the item contents of the well established 12 item version of the Hebrew adaptation (Zeidner, Nevo, \& Lipschitz, 1988) of Spielberger's (1980) Test Anxiety Inventory, as well as the Aca demic Emotions Questionnaire (AEQ; Pekrun et al., 2011). The new scale assessed worry (the cognitive component, 8 items) and emotionality (the affective physiological component, 8 items) for domain general academic anxiety and for each domain specific anxiety domain (i.e., academic anxiety in mathematics, German, and French). Additionally, the scale focused on two situations in school in which anxiety may be critical: anxiety during exams (four worry and four emotionality items per domain general or domain specific academic anxiety) and anxiety during classes (four worry and four emotionality items per domain general or domain spe cific or academic anxiety). Parallel item wording for worry and emotionality items was used across the two situations to control for item specific variance. In sum, the scale consisted of four items for worry and emotionality in each situation (i.e., exams and the classroom context) for each domain specific and domain general academic anxiety.

Additionally, one general item for each domain (e.g., "I am afraid of mathematics") and domain general academic anxiety ("I

Table 2

Criteria employed to evaluate the psychometric quality of the short forms and single-item measures of academic anxieties and academic self-concepts.

\begin{tabular}{|c|c|c|}
\hline $\begin{array}{l}\text { Psychometric } \\
\text { quality criterion }\end{array}$ & Description & Method \\
\hline Reliability & $\begin{array}{l}\text { Precision with which short forms and single-item measures measure the } \\
\text { latent construct that underlies the corresponding long scale }\end{array}$ & Reliability coefficient $\omega$ based on confirmatory factor analysis models \\
\hline $\begin{array}{l}\text { Information } \\
\text { reproduction }\end{array}$ & $\begin{array}{l}\text { Amount of information obtained by long scales that is reproduced by short } \\
\text { forms and single-item measures }\end{array}$ & $\begin{array}{l}\text { Correlations between the full-scale scores and the respective short } \\
\text { forms and single-item measures; Correction of the correlations for } \\
\text { overlapping error variance (Levy, 1967) }\end{array}$ \\
\hline $\begin{array}{l}\text { Relations in } \\
\text { nomological } \\
\text { network }\end{array}$ & $\begin{array}{l}\text { Degree to which short forms and single-item measures reproduce the } \\
\text { relations with constructs in the nomological network obtained by long } \\
\text { scales }\end{array}$ & $\begin{array}{l}\text { Differences in the correlations of the long scales and the short scales } \\
\text { (as well as of the single-item measures) with eight important } \\
\text { constructs in educational research }\end{array}$ \\
\hline
\end{tabular}


am afraid of most school subjects") was constructed, which served as the single item measure. Please note that the phrase "I am afraid of" refers to the German word "angst," which is a very common everyday language term that reflects a general level of anxiety rather than directly reflecting the worry or emotionality compo nents of the construct. The resulting full 17 item scales are pre sented in Table A2 of Appendix A.

Short-form measure (SF). The short forms consisted of three items from the long scale: (a) one item that represented the under lying construct best in terms of content validity, and (b) two addi tional items chosen from the full scale (see Table 3 for the wording of the chosen items; for a discussion of the development of the short scales, see Section 4.2. of the present paper). The selection of these two items was based on factor loadings as an item level index of internal item quality (Stanton et al., 2002). Specifically, we selected the two additional items for the short form measures in the following way: First, for each full scale, we ranked the items according to their standardized factor loadings. Then we averaged the ranks of each item across the four scales (i.e., one domain gen eral scale and three domain specific scales). Finally, to build the short scales for each construct, we chose the two items that had the highest averaged ranks. In this way, the resulting domain gen eral and domain specific scales resulted in parallel wording (see page 33 for a discussion of the advantages of this strategy). The number of items was chosen to be three for two reasons: It is the standard number of items used in large scale assessments such as PISA, and three indicators is the recommended (minimum) number of items needed to represent a latent factor in structural equation modeling (Kline, 2010).

Single-item measure (SI). Each item that was used as a single item measure (also included in the full scale and short form) was constructed with the aim of directly and maximally representing the essence of the academic anxiety definition (i.e., feelings of worry, nervousness, and uneasiness) using words that all respon dents could understand (Schaeffer \& Presser, 2003). Thus, the wording of the items was determined from a content perspective by choosing an expression most directly related to the concept of anxiety (i.e., "I am afraid of") and by integrating it into a sentence in which it was possible to add the different school domains as the objects of the sentences (e.g., "I am afraid of German class"; see Table 3 for the wording of all single item measures).

2.2.1.2. Academic self concept. Full scale (FS). To assess students' mathematics, German, French, and domain general academic self concepts, six items were employed from the Academic Self Description Questionnaire (ASDQ; Marsh, 1990a) or developed according to instructions given by Marsh (1990a). The basic struc ture of ASDQ is patterned after the SDQ and Byrne (1996a) noted that it can be assumed that the ASDQ yields the same high quality data as the Self Description Questionnaire (SDQ; Marsh, 1988, 1990b; Marsh \& O'Neill, 1984), which is considered to be one of the best self concept instruments available (e.g., Byrne, 1996b). For each domain, one additional item from the SDQ was added to the scale (e.g., for mathematics: "I am good at mathematics"; see Table 3), which also served as the single item measure in the pres ent study. Thus, the full scale for each domain specific academic self concept or the domain general academic self concept con sisted of seven items (full scales of domain general and domain specific academic self concepts are presented in Table A2 of Appendix A).

Short-form measure (SF). The short forms were chosen from the full scales based on the same rationale as the one described above for academic anxiety (see Table 3 for the wording of the cho sen items).

Single-item measure (SI). The items that were used as the sin gle item measures (also included in the full scale and short form) were constructed with the aim of directly and maximally commu nicating the essence of the academic self concept definition (see Section 1.1.2.) using words that all respondents could understand (Schaeffer \& Presser, 2003). Thus, the wording of the items was determined from a content perspective by choosing an expression most directly related to the self concept (i.e., "I am good at") and adding the different school domains as the objects of the sentences (e.g., "I am good at German"; see Table 3 for the wording of all sin gle item measures).

\subsubsection{Student characteristics}

To investigate the scales' relations to other important con structs in education, the following student characteristics were assessed (apart from available information regarding academic track and gender):

2.2.2.1. Student achievement. Domain specific achievement scores were assessed by comprehensive competency tests in mathemat ics, German reading comprehension, and French reading compre hension. Competency tests were developed by experts on the basis of extensive pilot studies. The difficulty of the competency tests was tied to the achievement levels of each academic track. Item scores were scaled by means of a unidimensional Rasch model with the ConQuest software (Wu, Adams, Wilson, \& Haldane, 2007), which allowed us to compare student performance across different tracks. The scales showed the following reliability estimates: $.82, .80$, and .80 for mathematics, German, and French achievement, respectively. In addition to domain specific achieve ments, general academic achievement was calculated as the means of the scores for mathematics, German, and French achievement in order to examine domain general and domain specific relations.

2.2.2.2. School satisfaction. School satisfaction was measured with three items ("I like going to my school," "If it were possible, I would prefer to go to another school" [reverse scored in all analy ses], "I feel comfortable at our school") with a scale reliability of Cronbach's $\alpha=.67$. Students responded to the items on a 4 point rating scale $(1=$ disagree, 2 =disagree somewhat, 3 =agree some what, and $4=$ agree) so that higher values indicated higher school satisfaction.

2.2.2.3. Students' socioeconomic status (SES). Students' socioeco nomic status (SES) was indicated by the highest International Socio Economic Index of Occupational Status (ISEI; Ganzeboom, de Graaf, Treiman, \& de Leeuw, 1992) of the student's father or mother as derived from student responses regarding parental occupation. Higher ISEI values indicated higher SES.

\subsection{Statistical analyses}

Missing data are unavoidable in any large scale assessment. Valid data for the measures of mathematics, German, and French achievement were available for 3873 students (99.99\%). The high est percentage of missing data was obtained for the socioeconomic status measure ( 2778 with valid data; $71.61 \%$ ). The reason for this missing data apart from missing responses was that we could not use all responses from the students because some of the descrip tions of parental occupations were too vague or obviously made up by the students. Complete data for the school satisfaction scale were available for 3806 students (98.11\%). To account for the pat tern of missing data as observed in the present study, the full infor mation maximum likelihood procedure (FIML) implemented in Mplus was used. Moreover, the "complex" option in Mplus (with classes as a cluster variable) was used to obtain standard errors and fit statistics corrected for the nonindependence of observa tions because the students were not independently sampled but 
Table 3

Items assessing academic anxiety and academic self-concept as included in the short form and single-item measures.

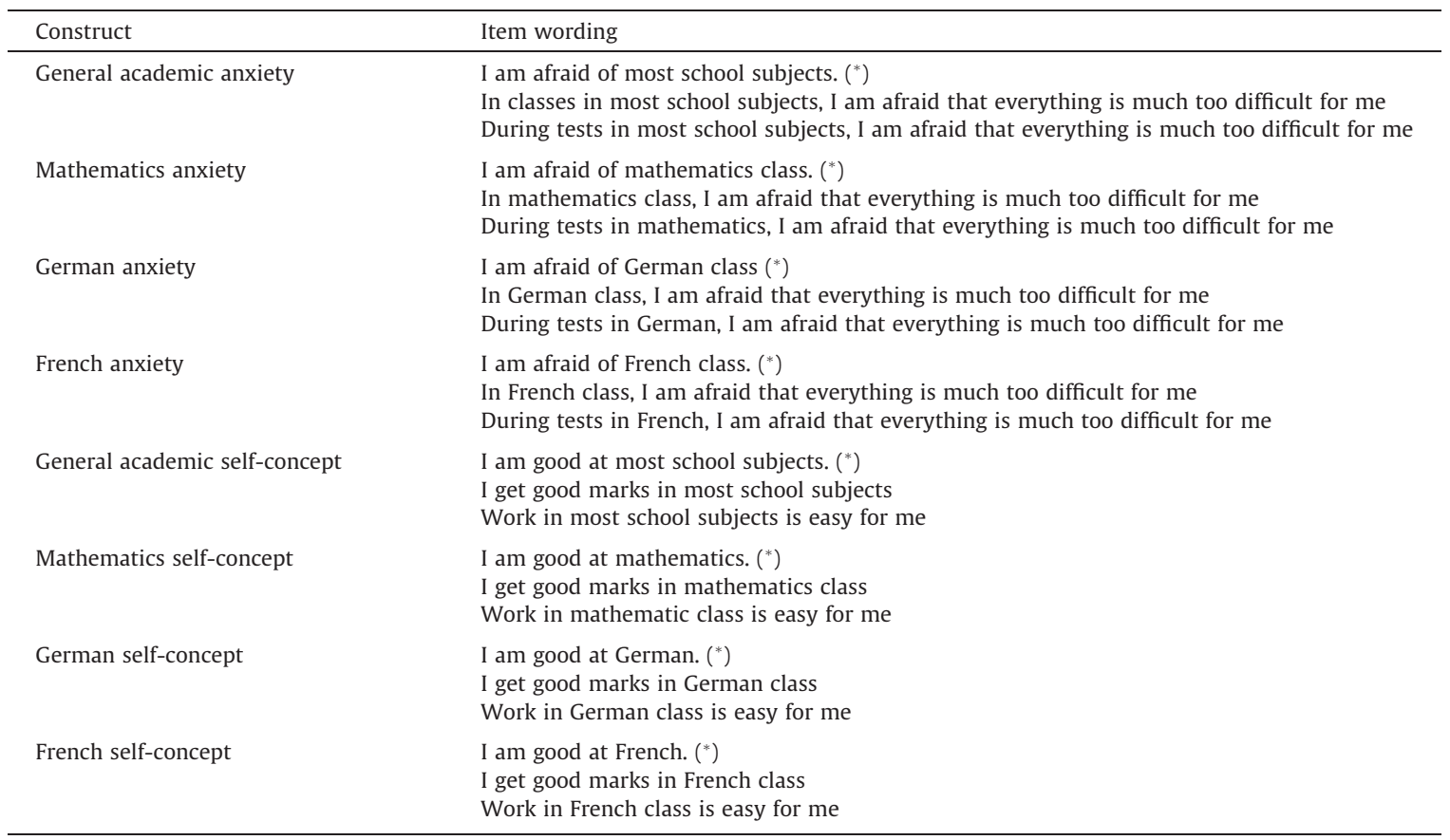

Note. Items marked with an asterisk represent items used as single-item measures.

rather nested within classes. Therefore, for the estimation of model parameters and confidence intervals, the MLR estimator was used. It offers an appropriate and robust to non normality of the data variant of the maximum likelihood estimator (ML) to be used with the complex option for data with nonindependence of observations (see Muthén \& Muthén, 1998 2010).

The psychometric qualities of the long scale, the short form, and the single item measure were rigorously examined with respect to the following criteria (see Table 2).

\subsubsection{Reliability}

To answer the question "How reliable are short forms and sin gle item measures?”, confirmatory factor analysis (CFA) models were used to estimate the model based reliability in terms of coef ficient $\omega$ (cf. Brunner, Nagy, \& Wilhelm, 2012; McDonald, 1999; Zinbarg, Revelle, Yovel, \& Li, 2005; Zinbarg, Yovel, Revelle, \& McDonald, 2006) for full scales, short forms, and single item mea sures of domain general and domain specific academic anxieties and academic self concepts. Values of $\omega$ can range from 0 (no reli ability) to 1 (perfect reliability). In contrast to the more widely used Cronbach's alpha coefficient, $\omega$ takes the congeneric nature of the respective measurement models into account (Brunner et al., 2012). The model based reliability $\omega$ of an item (or scale) may be defined as the proportion of variance accounted for by a latent construct (e.g., mathematics self concept) relative to observed score variance (Brunner et al., 2012). In the case of a sin gle item, the coefficient $\omega$ can be interpreted as the precision with which this item measures the latent construct as obtained from all items that constitute the long scale. Similarly, the estimated coef ficient $\omega$ of the short forms indicates the precision with which the three items from each short form measure the corresponding latent construct that underlies all items from a corresponding full scale.

To estimate $\omega$, a model with a single factor influencing all items of a certain total scale was estimated in a first step; thus, we tested a total of eight models. In a second step, we used only those model parameters obtained in the first step that were relevant for com puting $\omega$ for (a) the full scale, (b) the short form, or (c) the sin gle item measure. In each model (as analyzed in the first step), factor loadings and variances could vary across manifest measures (reflecting the assumption of congeneric measures). Additionally, in the models for the anxiety measures, the residuals were allowed to correlate to account for items with parallel wording (Little, Preacher, Selig, \& Card, 2007). Model fit was examined by means of global fit indices as recommended by Hu and Bentler (1998) and commonly used in studies applying structural equation mod els: the chi square test of overall model fit, and descriptive fit sta tistics such as the Standardized Root Mean Square Residual (SRMR), the Comparative Fit Index (CFI), and the Root Mean Square Error of Approximation (RMSEA). SRMR values below .08, RMSEA values below .05 , and CFI values greater than .95 are considered to indicate good model fit (Hu \& Bentler, 1998). RMSEA values between .05 and .08 indicate moderate fit (Browne \& Cudeck, 1993).

\subsubsection{Amount of reproduced information}

The second research question was "How well do short forms and single item measures reproduce the information obtained by long scales?" To answer this question, we computed Pearson corre lations between the full scale scores and the scores on the respec tive short forms and single item measures. As the scores on the short forms (SF) and single item measures (SI) were extracted from the long scales (LS) in which the corresponding SF and SI were embedded, the corresponding correlation between the short scales and long scales were artificially inflated due to measurement error shared by the part of the scale (SF or SI) and its whole (FS; cf. Girard \& Christensen, 2008). Therefore, we applied a statistical correction for this overlapping error variance (Levy, 1967). Levy's correction provides a correlation between the short scales and the long scale "as if" obtained from separate SF/SI and FS administrations by removing the covariance due to correlated measurement error between the SF/SI and the FS (Girard \& Christensen, 2008). 


\subsubsection{Nomological network}

To answer the question "How well do short forms and single item measures reproduce the relations in the nomological network obtained by long scales?" we examined the relations between the different scale forms and other important constructs in educational research (i.e., student achievement, school satisfaction, gender, academic track, and socioeconomic status). To this end, for each student characteristic, the difference between the Pearson correla tion with the full scale and the Pearson correlation with the short form (as well as the single item Pearson correlation) and the 95\% confidence intervals for each difference between the two correla tions were calculated according to the formula provided by Cheung (2009). In addition, we calculated the averaged difference between the correlations across the eight criteria.

\subsubsection{Polyserial correlations}

We also compared the Pearson correlations between the single item measures and the full scales (as described in Section 2.3.2.) as well as between the single item measures and the external criteria (as described in Section 2.3.3.) with results obtained using polyse rial correlations, which perhaps better account for the rating scale nature of single item measures. To this end, based on the underly ing normally distributed continuous variable behind the ordinal single item measures, polyserial correlations were estimated with Mplus. We decided to focus our results on the Pearson correlations as they enable the results of our study to be compared with the majority of other studies on single item measures that applied Pearson correlations. Therefore, if not otherwise indicated, the reported correlations represent Pearson correlations.

\section{Results}

\subsection{Academic anxiety}

\subsubsection{Reliability}

Confirmatory factor analyses indicated that the 17 item one factor model with correlated errors had adequate fit according to the descriptive fit statistics for the domain general academic anx iety scale and the domain specific anxiety scales: mathematics, German, and French anxiety. The $p$ values for the $\chi^{2}$ statistics for all the models were below $p<.01$ indicating statistically significant discrepancies between the hypothesized model and the observed data. However, it is well known that the $\chi^{2}$ statistic is sensitive to sample size, whereby trivial model misfit may result in signifi cant values with modest sample sizes (Iacobucci, 2010). Given the large sample size in the present study, we therefore focused our evaluation of model fit on the descriptive fit indices. The model fit results and information on the factor loadings we obtained are presented in Table A3 of Appendix A. Moreover, Table B1 of Appen dix $B$ contains the values of the highest modification indices and their locations within each model. Notably, we found no empirical evidence to justify model modifications on substantive grounds.

The model based reliability in terms of coefficient omega (see Table 4) was relatively high for all anxiety full scales ranging from $\omega=.85$ for domain general academic anxiety to $\omega=.89$ for the French anxiety scale. The reliabilities of the short forms were slightly lower than for the full scale; however, they were still sat isfactory, ranging from $\omega=.75$ for domain general academic anxi ety and French anxiety to $\omega=.78$ for mathematics anxiety. The reliabilities of the items representing the single item measures, however, were relatively low, ranging from $\omega=.22$ for German anxiety to $\omega=.29$ for domain general and mathematics anxiety.

\subsubsection{Information reproduction}

As shown in Table 4, the correlations between the full scales and the short forms were relatively high, ranging from $r=.88$ for domain general academic anxiety to $r=.92$ for mathematics anxi ety. The single item measures showed substantial correlations with the respective full scales with $r_{\mathrm{s}}$ ranging from .50 for German anxiety to .56 for mathematics anxiety. The correlations that were corrected for shared error variance (Levy, 1967) were lower, rang ing from .83 to .88 for the short forms that assessed domain gen eral and mathematics anxiety, respectively. The corrected correlations between the full scales and the single item measures ranged from .46 to .51 for German anxiety and mathematics anxi ety, respectively.

The polyserial correlations of the single item measures with the respective full scales are depicted in Table B2 in Appendix B. Nota bly, the use of polyserial correlations did not change the conclusion of our study: The polyserial correlations even showed somewhat stronger similarities between the single item measure and the respective longer scale with a maximal difference between the Pearson and polyserial correlations of .07 (see Table B2 for the comparison).

\subsubsection{Nomological network}

The correlations of the academic anxiety full scales, short forms, and single item measures with student characteristics are pre sented in Table 4 and Fig. 1. In all domains, the short forms showed patterns that were very similar to the full scales in their correla tions with the external criteria. This is reflected by the small mean absolute differences between correlations obtained for the full scales and the short forms (.02 for all academic anxiety domains). The respective differences in correlations between long scales and short forms and their 95\% confidence intervals are shown in the bottom panel of Table 4 . None of the correlations between the short forms and the student characteristics differed significantly from the correlations between the respective full scales and these external variables $(-.04<\Delta r<.03)$.

The patterns of correlations between the single item measures and student characteristics diverged slightly more from the pat terns for the full scales than the patterns for the short forms did; the mean absolute differences for single items ranged from .04 for domain general academic anxiety to .07 for mathematics and German academic anxiety. The respective differences in correla tions ranged from -.14 to .05 (see Table 4). The patterns of corre lations between the three versions of the scales and other student characteristics are displayed in Fig. 1.

The polyserial correlations of the single item measures with the student characteristics (see Table B2 in Appendix B) showed result patterns that were comparable to those computed with the Pear son correlations (with a maximal absolute difference between the Pearson and polyserial correlations of .04).

\subsection{Academic self concept}

\subsubsection{Reliability}

Confirmatory factor analyses indicated that the seven item one factor model had a good fit to the data for the German academic self concept scale and French academic self concept scale accord ing to the descriptive fit statistics (see Table A3 in Appendix A). The fits for the domain general and mathematics self concepts were somewhat worse (see Table A3): SRMR values were in the acceptable range, but the CFI and RMSEA values were on the bor derline of the recommended cut off criteria for the domain general self concept scale, and these values fell outside of the recom mended cut off criteria for the mathematics self concept scale. The $\chi^{2}$ statistics for all the models were significant (all $p s<.01$ ).

When the model fit did not match the required benchmark val ues (as for domain general academic self concept and mathemat ics self concept), we placed more emphasis on the SRMR index because this index is based on the average residual correlations 


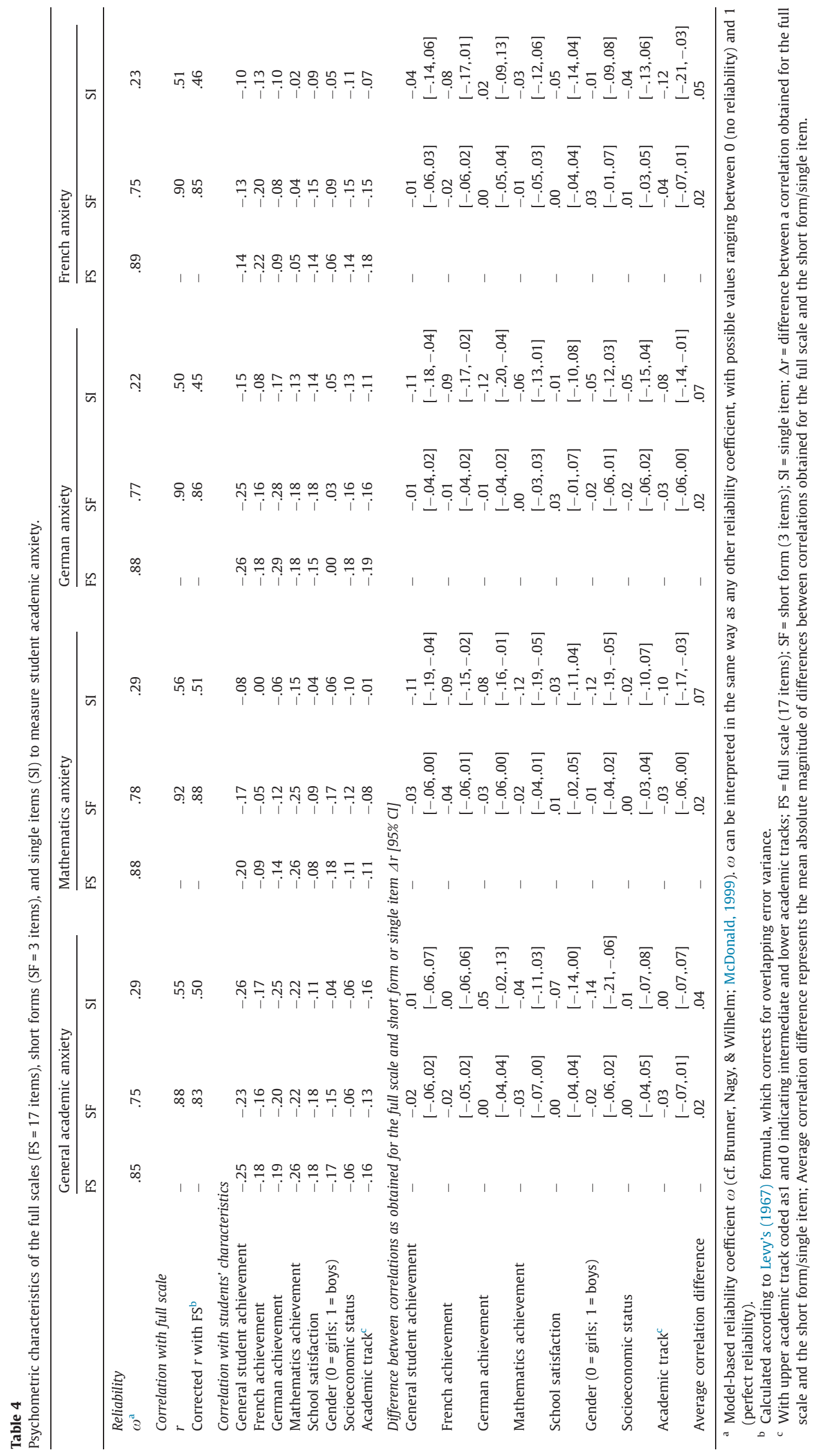



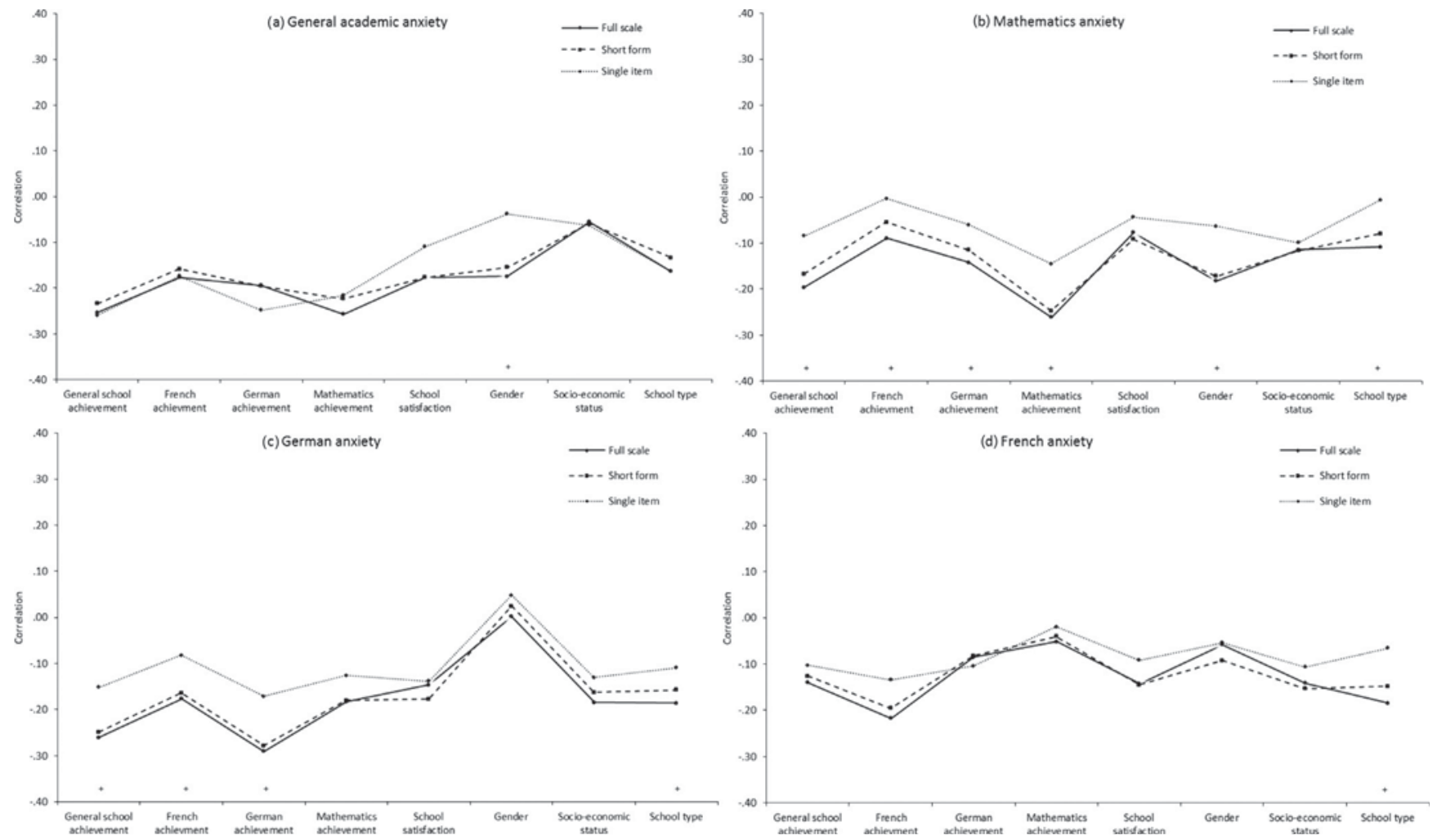

Fig. 1. Similarities in the correlational patterns of the full scale (17 items), short form ( 3 items), and single item with student achievement, satisfaction with school, and sociodemographic characteristics (gender, socioeconomic status, and academic track) for (a) general academic anxiety, (b) mathematics anxiety, (c) German anxiety, and (d) French anxiety; + indicates significant difference between the single item and the full scale $\left(p<.05\right.$; two-sided); ${ }^{*}$ indicates significant difference between the short form and the full scale $(p<.05 ;$ two-sided $)$.

and thus provides information about the overall quality of the approximation (irrespective of the parsimony of the model). In such cases, we also carefully examined the modification indices. The largest modification indices and their locations within each model are given in Table B1 in Appendix B. Although the modifica tion indices suggested incorporating the correlations between the residuals of "I learn things quickly in mathematics"|"I learn things quickly in most school subjects" with "I am good at mathematics"| "I am good at most school subjects", we found no empirical evi dence to justify model modifications on substantive grounds. Our goal was to select a model that had substantive meaning and was more parsimonious than the alternative models.

The model based reliability in terms of coefficient omega (see Table 5) was high for all self concept full scales with the mathe matics and French self concept scales showing the highest reliabil ity $(\omega=.92)$. The reliabilities of the domain general and the German self concept scales were $\omega=.82$ and .88 , respectively. The reliabilities of the short forms of the French and mathematics self concept scales were also relatively high $(\omega=.89)$. The short forms of the domain general and German self concepts showed satisfactory reliabilities ( $\omega=.75$ and .83 , respectively). The reliabil ities of the single item measures for the mathematics and French self concepts were also satisfactory ( $\omega=.72$ and .71 , respectively). The domain general and German self concept reliabilities of sin gle item measures were lower $(\omega=.44$ and .54 , respectively). Please note that as omega is based on parameter estimates (i.e., estimates of factor loadings and factor variances) that are derived for a certain CFA model, the proper interpretation of omega requires that the target model provides a good fit to the empirical data (Bentler, 2009; McDonald, 1999; Yang \& Green, 2010). Therefore, the omega values obtained for the domain general and mathematics self concept models should be interpreted with cau tion because the fits of these models to the data were modest.

\subsubsection{Information reproduction}

As shown in Table 5, the correlations between the full scales and the short forms were relatively high, ranging from $r=.92$ for the domain general academic self concept to $r=.97$ for the math ematics self concept. The single item measures showed slightly lower correlations with the respective full scales with the highest correlations for the mathematics and French academic self con cepts $(r=.88$ and $r=.87$, respectively). For the domain general and German academic self concepts, the correlations were $r=.74$ and .79, respectively. The corrected (Levy, 1967) correlation coeffi cients between the full scales and the short forms ranged from .80 for the domain general self concept to .91 for the mathematics and French self concepts. For single items, they were between $r=.63$ and .83 for the domain general academic self concept and mathe matics self concept, respectively.

The polyserial correlations between the single item measures and the respective full scales (see Table B2 in Appendix B) showed even slightly stronger overlaps in variance between the single item measures and the respective long scales (maximal difference between the Pearson and polyserial correlations $=.05$ ).

\subsubsection{Nomological network}

The correlations of the self concept full scales, short forms, and single items with student characteristics are presented in Table 5 and Fig. 2. The short forms showed patterns of correlations to the external criteria that were very similar to the patterns shown by the full scales in all domains. This is reflected by small mean abso lute differences between correlations obtained for the full scales 


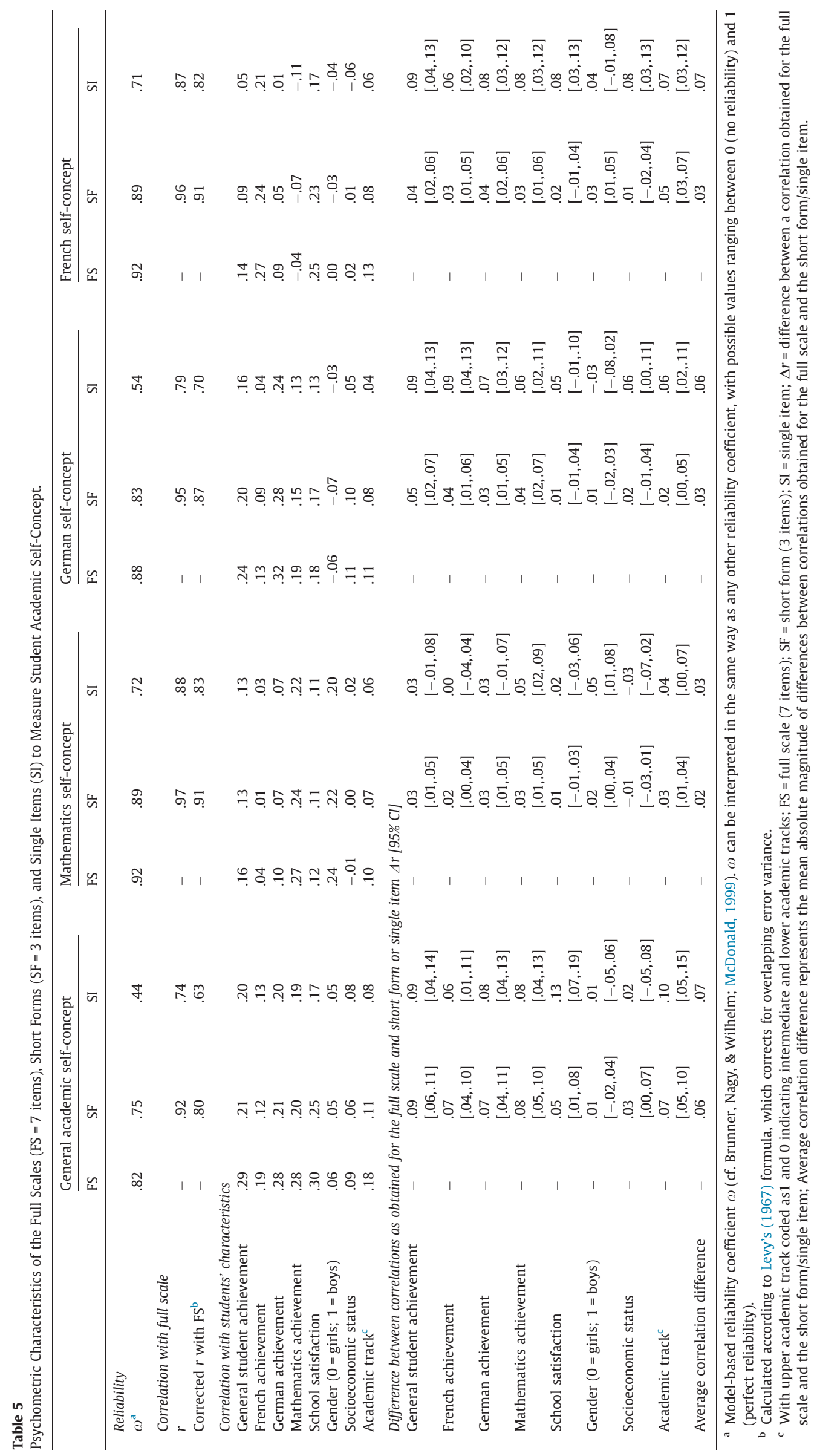



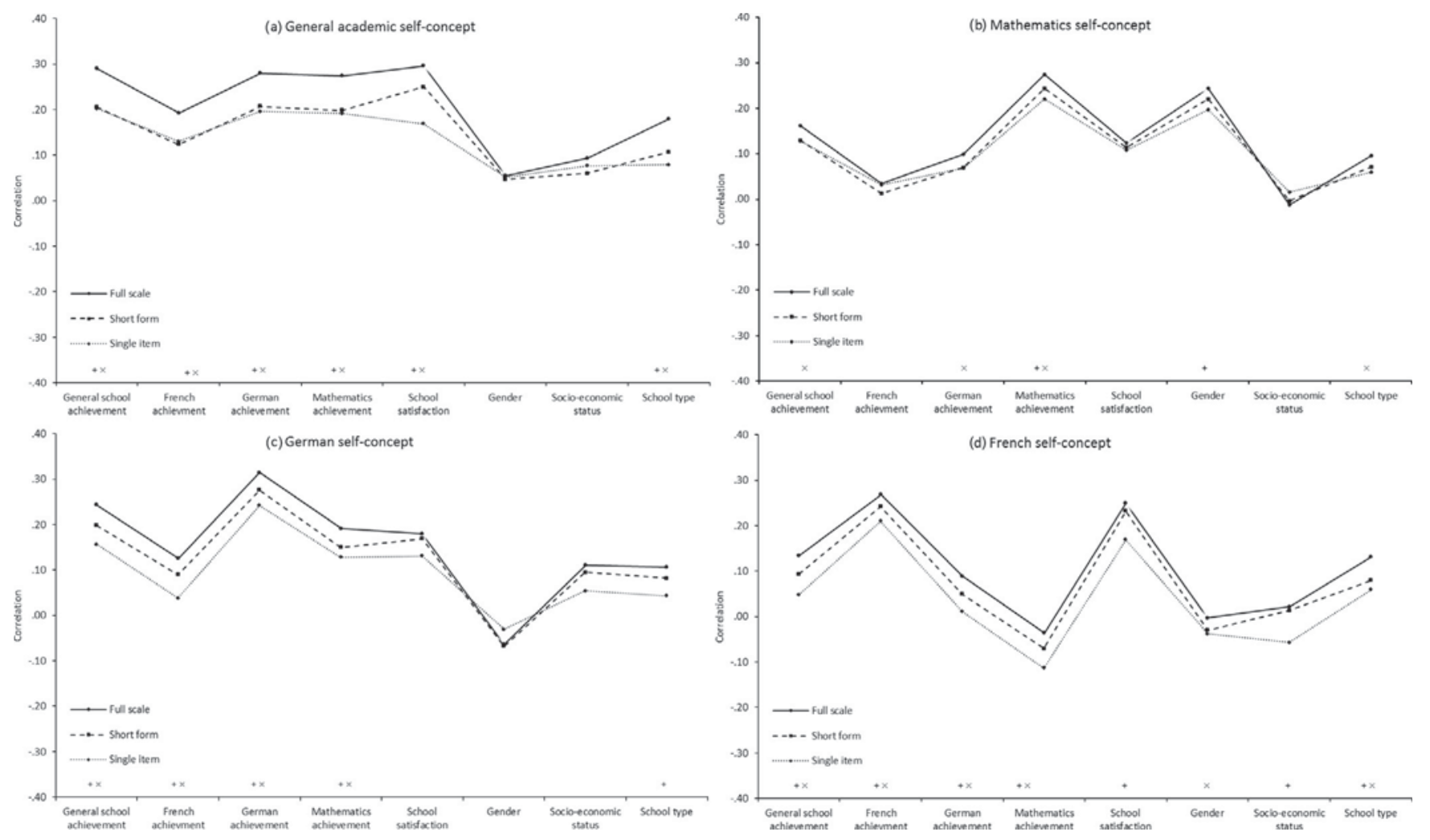

Fig. 2. Similarities in the correlational patterns of the full scale ( 7 items), short form ( 3 items), and single item with student achievement, satisfaction with school, and sociodemographic characteristics (gender, socioeconomic status, and academic track) for (a) general academic anxiety, (b) mathematics anxiety, (c) German anxiety, and (d) French anxiety; + indicates significant difference between the single item and the full scale $\left(p<.05 ;\right.$ two-sided); ${ }^{*}$ indicates significant difference between the short form and the full scale $(p<.05 ;$ two-sided $)$.

and the short forms (.02 to .03 for all domain specific self con cepts; the mean absolute difference was higher for domain general academic self concept: .06). The respective differences in correla tions and their 95\% confidence intervals are shown in Table 5; they ranged between -.01 and .09 . The mean absolute differences for single items were slightly higher than for short forms, ranging from .03 for mathematics self concept to .07 for domain general and French self concepts. The respective differences in correlations ranged between -.03 and .13 . The patterns of correlations between the three versions of the scales and other student characteristics are displayed in Fig. 2.

The polyserial correlations between the single item measures and the student characteristics (see Table B2 in Appendix B) showed patterns of results that were similar to those obtained with the Pearson correlations (with a maximal absolute difference between the Pearson and polyserial correlations of .03).

\section{Discussion}

\subsection{Short form and single item measures versus full scales}

We analyzed three vital questions in measurement to examine the psychometric characteristics of short forms (three items) and single item measures of domain general and domain specific (i.e., mathematics, German, and French) academic anxieties and academic self concepts (see Table 2):

(1) How reliable are short forms and single item measures? The short forms for all constructs showed high reliabilities, but they were still lower than those of the full scales. Not sur prisingly, the reliabilities of all single item measures were lower than the corresponding short form and full scale reliabilities.

(2) How well do short forms and single item measures repro duce the information obtained by long scales? All short forms showed substantial correlations with the long scales, even after removing the common error variance (Levy, 1967). Whereas single item measures of academic self concept also showed substantial correlations with the full scales, the cor relations between single item measures of academic anxi eties and the full scales were low or modest at best.

(3) How well do short forms and single item measures repro duce the relations in the nomological network obtained by long scales? The short forms for measuring academic anxiety and academic self concept demonstrated correlational pat terns with important educational student characteristics (i.e., achievement, school satisfaction, gender, SES, and aca demic track) that were similar to those obtained with the full scales. Notably, these results were also well aligned with the results typically found in previous studies (see Table 1). Also, correlations between single item measures and stu dent characteristics were consistent in direction and signifi cance with the corresponding correlations of long scales and results from previous empirical studies, resulting in essen tially the same pattern of correlations as the full scales. However, the correlational patterns between the single item measures and external criteria were slightly more divergent from those obtained with the full scales than the corre sponding correlations obtained with the short forms.

It has to be noted that the choice of the robust continuous ML may have introduced negative bias into the estimates of the factor 
loadings and consequently produced lower bound estimates of reliability $(\omega)$. Specifically, the study by Rhemtulla et al. (2012) indicates that when variables have fewer than five categories, MLR can lead to underestimations of factor loadings (with stronger biases for asymmetrical response distributions than for symmetri cal distributions). Therefore, given that our measures had four cat egories and the responses to academic anxiety items are usually not symmetrical (see Table B3 in Appendix B for supplementary material showing item category frequency distributions for the academic anxiety items), we assume that there was a greater underestimation of factor loadings and consequently a greater underestimation of the reliability estimates for the academic anx iety scales than for the academic self concept scales because the item responses for the self concept items showed higher degrees of symmetry than the academic anxiety items did (see Table B4 in Appendix B for the item category frequency distributions of the academic self concept items).

In the following, we discuss these results with regard to the purposes for which short form and single item measures of aca demic anxieties and academic self concepts might be particularly useful or not.

First, as our results show, despite lower reliabilities, the rela tions of the short forms and single item measures to other impor tant student characteristics remained similar to those obtained with the full scales. These results justify the employment of short forms and single item measures in research contexts in which the main interest of a study is to gain a general understanding of the relations between multiple constructs, especially in studies in which multiple constructs or constructs in multiple domains need to be assessed in a limited amount of time (e.g., longitudinal stud ies with measurement burst designs or large scale assessment studies). Moreover, single item measures can be particularly useful in studies that use experience sampling for ambulatory assess ments or other technologies that focus on state emotions. Here, (a) responding to multiple items may influence the state emotion itself and (b) during the time needed to respond, the state emotion may change (see Goetz et al., 2007). These problems can be circum vented by the use of single item measures. Of note, the present paper addresses the measurement of constructs on the trait level, and although our results are encouraging for using single item self reports of academic anxiety and self concept, the psychomet ric properties of these items for assessing constructs at the state level should be addressed in further research (cf. Goetz et al., 2013).

Second, with regard to the latent nature of academic anxieties and academic self concepts, in structural equation modeling, a sta tistical technique with quickly increasing popularity, valid and reli able single item measures may be particularly useful as reference indicators to set the metric of latent constructs (see also Eid, Lischetzke, Nussbeck, \& Trierweiler, 2003, for a more in depth dis cussion of the importance of "gold standard" measures).

Third, obviously, given the relatively low reliabilities of single item measures and short forms, they cannot be routinely used to replace established multi item instruments, especially in situations in which the high reliability of measurement plays an essential role. For example, short versions of long scales are not appropriate for individual diagnostic purposes when high stake decisions depend on the assessment outcome. Nevertheless, short forms and perhaps also single item scales can be suitable for screening purposes to identify individuals who score above or below certain thresholds. In a second step, more detailed and focused diagnoses using longer measurement inventories can be applied.

Taken together, our results are in line with the conclusions of other studies that a short version (Marsh, Ellis, Parada, Richards, \& Heubeck, 2005) or even a single item measure of an original long scale may provide suitable alternatives (e.g., Robins et al., 2001). In particular, single item self reports may be adequate when a con struct is concrete, highly schematized for most individuals, unidi mensional in content, and when it primarily reflects subjective experience (Robins et al., 2001). The academic self concept fulfills all of these criteria, and the results from our study support this conclusion. Interestingly, as our analysis of single item measures of academic anxieties shows, even when a construct is more com plex and consists of multiple components (e.g., worry and emo tionality for academic anxiety), a single item may still provide an appropriate measure when there is a strong single common factor underlying the construct indicators (i.e., when a construct shows essential unidimensionality; Reise, Moore, \& Haviland, 2010; Reise, Morizot, \& Hays, 2007) and when the researcher is interested in the global level of the construct. However, if a detailed investi gation of the nature or structure of a construct is the focus of a study, multiple item scales should be used.

\subsection{How to develop a short form measure}

An important issue that also needs to be discussed is how short scales can and should be developed. Our results do not imply that just any short forms and single item measures can be used to assess academic anxieties and self concepts. A thorough process of scale construction is a necessary prerequisite for creating a sound measurement instrument. A common practice is to shorten an existing long scale. However, in some cases, constructing a new short scale by developing new items may be a better option (e.g., when the existing items are of poor quality). Moreover, when the original scale items from the existing scales are very specific and each item assesses a detailed facet of a construct, but the short scale items should assess the general level of a construct, it may be recommendable to develop new, more general items (see Fig. 3 for the major steps of both strategies and a comparison between them).

In the present study, we connected the two strategies by enrich ing existing well validated instruments with items designed to assess the general level of each construct. This strategy has the advantage that by establishing the measurement model of the extended scale, the model based reliability of the single item mea sures can be estimated.

Moreover, in our study and in line with Fig. 3, we began our construction of the short scales by adding general items that directly and maximally capture the essence of the academic self concept definition to items from well validated long scales. To choose the "best" items from this item pool to be used in the short form, we adhered to the following rationale (for further criteria on item choice, see Hinkin, 1998; Marsh et al., 2005; Smith et al., 2000, or Stanton et al., 2002): (a) content considerations resulted in choosing the general items as items that prototypically reflected the contents of the constructs, and (b) after analyzing the psycho metric properties of the items, we chose the two items that had the highest average factor loadings across different domains. The resulting short forms measured the constructs in all domains with parallel wording, which allows for comparability and tests of invariance across domains (see Marsh et al., 2013). However, when developing scales, if the goal is not to create scales that measure different domains with parallel wording, another possibility would be to choose the items showing the highest factor loadings for each scale. Such an approach leads to slight increases in the reliabilities of the specific scales. Moreover, it may be not advisable or it may even be impossible to develop scales with parallel wording across domains if the wording of an item is specific to one domain so that the application of the wording of this item to another domain would result in a strange sounding item or the resulting item would not make sense. 


\section{Developing new items}

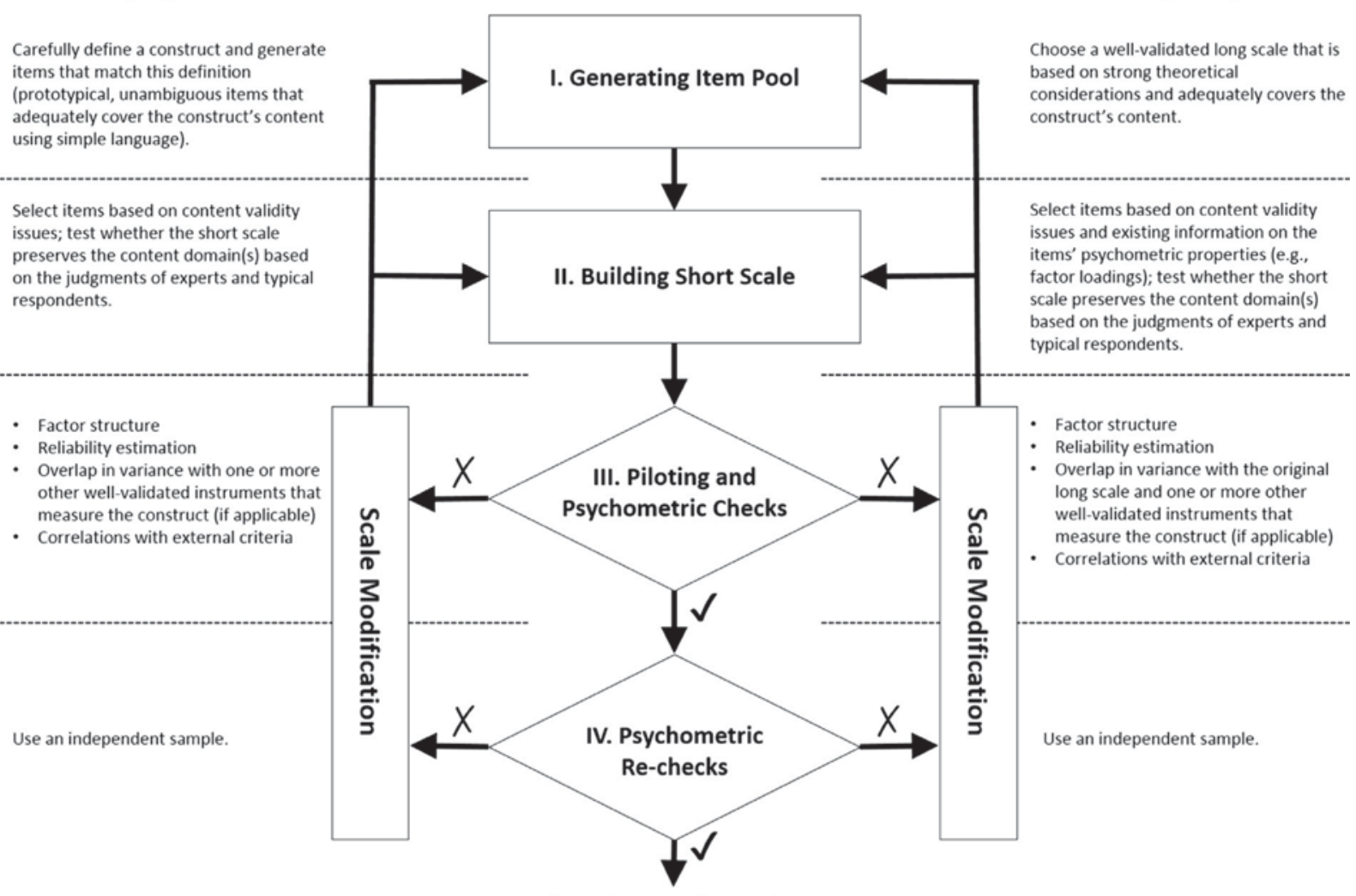

Final Short-Scale-Version

Fig. 3. Major stages in the development of the short(ened) scales; based on Haynes, Richard, \& Kubany, 1995; Hinkin, 1998; Marsh et al., 2005; Smith et al., 2000; Stanton et al., 2002.

\subsection{Limitations of the present study}

First, the generalizability of the results from this study may be limited due to the fact that the data were obtained only from a rep resentative sample of adolescents in Luxembourg. Although the short forms and single item measures reproduced the nomological network of academic anxiety and the academic self concept as was typically found in previous research, whether the findings are gen eralizable to students in other countries and to students of other ages remains an open question. Second, the short forms and the single item measures were administrated as part of the corre sponding full scales. This procedure may be problematic as the relations between the brief measures and the full scale can be overestimated because of the correlated measurement error that is shared by short forms and full scales when the short form is administrated as part of the parent measure. Although we statisti cally controlled for shared error with Levy's correction (1967), fur ther research needs to more accurately assess agreement between

Table A1

Multi-matrix design of the present study: measures and number of students per booklet.

\begin{tabular}{|c|c|c|c|c|c|c|}
\hline \multirow[t]{2}{*}{ Student characteristic } & \multicolumn{6}{|c|}{ Booklet (number of students) } \\
\hline & $\begin{array}{l}1 \\
(676)\end{array}$ & $\begin{array}{l}2 \\
(676)\end{array}$ & $\begin{array}{l}3 \\
(520)\end{array}$ & $\begin{array}{l}4 \\
(685)\end{array}$ & $\begin{array}{l}5 \\
(699)^{\mathrm{a}}\end{array}$ & $\begin{array}{l}6 \\
(540)\end{array}$ \\
\hline Mathematics achievement & $\mathrm{X}$ & $\mathrm{X}$ & $\mathrm{X}$ & $\mathrm{X}$ & $\mathrm{X}$ & $\mathrm{X}$ \\
\hline German achievement & $\mathrm{X}$ & $\mathrm{X}$ & $\mathrm{X}$ & $\mathrm{X}$ & $\mathrm{X}$ & $\mathrm{X}$ \\
\hline French achievement & $\mathrm{X}$ & $\mathrm{X}$ & $\mathrm{X}$ & $\mathrm{X}$ & $\mathrm{X}$ & $\mathrm{X}$ \\
\hline School satisfaction & $\mathrm{X}$ & $\mathrm{X}$ & $\mathrm{X}$ & $\mathrm{X}$ & $\mathrm{X}$ & $\mathrm{X}$ \\
\hline Parental occupation questions & $\mathrm{X}$ & $\mathrm{X}$ & $\mathrm{X}$ & $\mathrm{X}$ & $\mathrm{X}$ & $\mathrm{X}$ \\
\hline Mathematics anxiety (FS) & $\mathrm{X}$ & & & & & \\
\hline German anxiety (FS) & & $\mathrm{X}$ & & & & \\
\hline French anxiety (FS) & & & $\mathrm{X}$ & & & \\
\hline General academic anxiety (FS) & & & & $\mathrm{X}$ & & \\
\hline Mathematics self-concept (FS) & & & & & $\mathrm{X}$ & \\
\hline German self-concept (FS) & & & & & $\mathrm{X}$ & \\
\hline General academic self-concept (FS) & & & & & $\mathrm{X}$ & \\
\hline French self-concept (FS) & & & & & & $\mathrm{X}$ \\
\hline
\end{tabular}

Note. Numbers in brackets indicate the number of students who completed a certain booklet; $\mathrm{X}$ indicates that a measure of a certain student characteristic was included in a certain booklet.

FS = Full scale.

a The number of students differed between the specific scales: $n=690$ for mathematics self-concept, $n=699$ for German self-concept, and $n=693$ for domain-general selfconcept. 
long scales and short scales by independently administering all forms to the same sample. Pfeiffer, Hagemann, and Backenstrass (2011) introduced a procedure in which subjects are randomly assigned to different groups that are administered different combi nations of the full scales and the shortened versions. Third, we did not investigate the factor structures of the short forms and did not recheck the psychometric properties of the short forms and the single item measures using an independent sample as would be an appropriate scale development procedure (see Fig. 3). Fourth, further research is needed to confirm the psychometric properties of the one and three item measures when administered by them selves. It can be argued that by administering only short scales, the subjects' responses to these items might differ from their answers when short scales are administered together will long scales. Spe cifically, as short scales reduce item redundancy and the resulting fatigue and irritation of the respondents, the respondents may thus answer more conscientiously and carefully, thereby resulting in more appropriate reliability and validity estimates. Fifth, we could not estimate the test retest stability of the short forms and single items as we did not have longitudinal data. Thus, further research is needed to determine whether there would be any substantial loss in test stability when using the short scales instead of the full scales. Sixth, it would also be important to develop and investigate the psychometric properties of single items for different compo nents of academic anxiety (e.g., worry or emotionality) to be used for economic assessment in studies that focus on specific facets of academic anxiety (e.g., to investigate the hypothesis that the worry component of academic anxiety will have effects on academic out comes that are distinct from those of the emotionality component). Finally, further research is needed to answer the question of

Table A2

Items of full scales for domain-general and domain-specific academic anxieties and self-concepts.

\begin{tabular}{|c|c|c|}
\hline Construct & Item name & Item wording \\
\hline Domain-general academic anxiety & $\begin{array}{l}\text { AX_g1 } \\
\text { AX_g2 } \\
\text { AX_g3 } \\
\text { AX_g4 } \\
\text { AX_g5 } \\
\text { AX_g6 } \\
\text { AX_g7 } \\
\text { AX_g8 } \\
\text { AX_g9 } \\
\text { AX_g10 } \\
\text { AX_g11 } \\
\text { AX_g12 } \\
\text { AX_g13 } \\
\text { AX_g14 } \\
\text { AX_g15 } \\
\text { AX_g16 } \\
\text { AX_g17 }\end{array}$ & 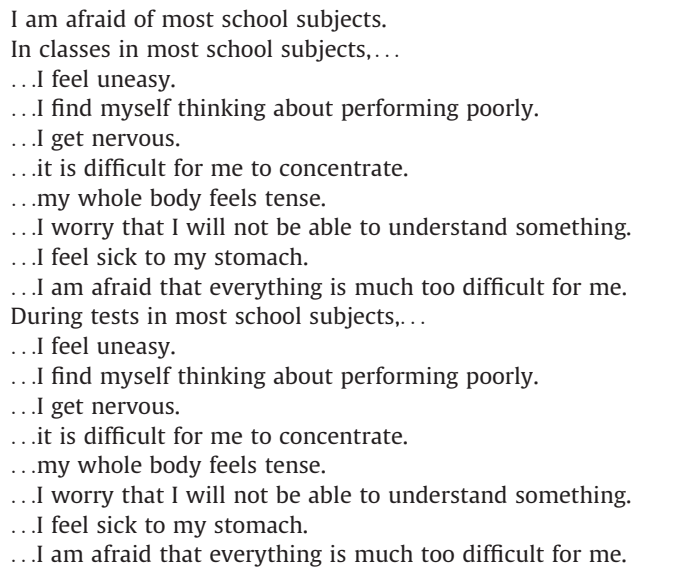 \\
\hline Domain-specific academic anxieties & $\begin{array}{l}\text { AX_[D]1 } \\
\text { AX_[D]2 } \\
\text { AX_[D]3 } \\
\text { AX_[D]4 } \\
\text { AX_[D]5 } \\
\text { AX_[D]6 } \\
\text { AX_[D]7 } \\
\text { AX_[D]8 } \\
\text { AX_[D]9 } \\
\text { AN_[D]10 } \\
\text { AX_[D]11 } \\
\text { AX_[D]12 } \\
\text { AX_[D]13 } \\
\text { AX_[D]14 } \\
\text { AX_[D]15 } \\
\text { AX_[D]16 } \\
\text { AX_[D]17 }\end{array}$ & 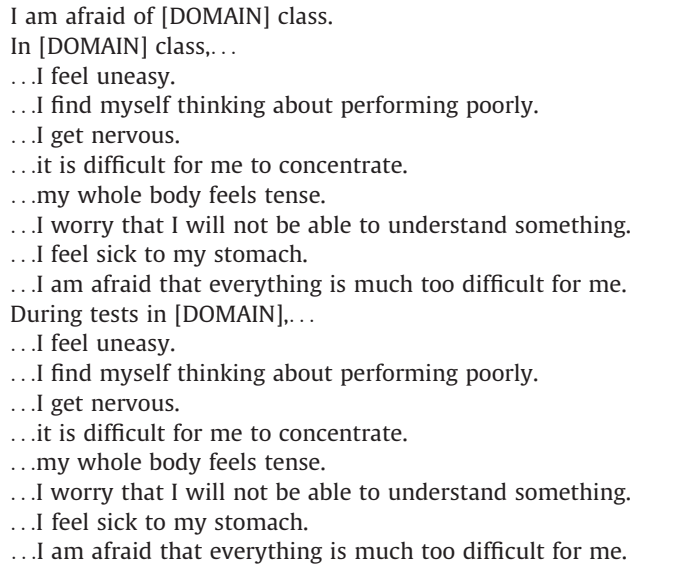 \\
\hline Domain-general academic self-concept & $\begin{array}{l}\text { SC_g1 } \\
\text { SC_g2 } \\
\text { SC_g3 } \\
\text { SC_g4 } \\
\text { SC_g5 } \\
\text { SC_g6 } \\
\text { SC_g7 }\end{array}$ & $\begin{array}{l}\text { I learn things quickly in most school subjects. } \\
\text { I am good at most school subjects. } \\
\text { I get good marks in most school subjects. } \\
\text { I am hopeless when it comes to most school subjects. } \\
\text { Work in most school subjects is easy for me. } \\
\text { I have always done well in most school subjects. } \\
\text { Compared to others my age I am good at most school subjects. }\end{array}$ \\
\hline Domain-specific academic self-concepts & $\begin{array}{l}\text { SC_[D]1 } \\
\text { SC_[D]2 } \\
\text { SC_[D]3 } \\
\text { SC_[D]4 } \\
\text { SC_[D]5 } \\
\text { SC_[D]6 } \\
\text { SC_[D]7 }\end{array}$ & $\begin{array}{l}\text { I learn things quickly in [DOMAIN]. } \\
\text { I am good at [DOMAIN]. } \\
\text { I get good marks in [DOMAIN] class. } \\
\text { I am hopeless when it comes to [DOMAIN]. } \\
\text { Work in [DOMAIN] class is easy for me. } \\
\text { I have always done well in [DOMAIN]. } \\
\text { Compared to others my age I am good at [DOMAIN]. }\end{array}$ \\
\hline
\end{tabular}

Note. To assess domain-specific constructs [DOMAIN] was replaced by mathematics, German, and French, respectively; [D] in item names was replaced by "M" for mathematics, "G" for German, and "F" for French. 
Table A3

Fit statistics and distributions of standardized factor loadings as obtained for measurement models of motivational-affective student characteristics.

\begin{tabular}{|c|c|c|c|c|c|c|c|c|}
\hline \multirow[t]{2}{*}{ Construct (number of items) } & \multirow[t]{2}{*}{$\chi^{2}$} & \multirow[t]{2}{*}{$\mathrm{df}$} & \multirow[t]{2}{*}{ CFI } & \multirow[t]{2}{*}{ RMSEA } & \multirow[t]{2}{*}{ SRMR } & \multicolumn{3}{|c|}{ Standardized factor loadings } \\
\hline & & & & & & Min & $M d n$ & $\operatorname{Max}$ \\
\hline \multicolumn{9}{|l|}{ Academic anxiety } \\
\hline General academic anxiety (17) & 102.1 & 55 & .99 & .04 & .02 & .46 & .70 & .84 \\
\hline Mathematics anxiety (17) & 132.4 & 55 & .99 & .05 & .02 & .54 & .76 & .87 \\
\hline German anxiety (17) & 113.5 & 55 & .99 & .04 & .02 & .47 & .74 & .85 \\
\hline French anxiety (17) & 140.7 & 55 & .98 & .05 & .02 & .48 & .73 & .83 \\
\hline \multicolumn{9}{|l|}{ Academic self-concept } \\
\hline General academic self-concept (7) & 77.7 & 14 & .94 & .08 & .04 & .24 & .70 & .77 \\
\hline Mathematics self-concept (7) & 148.3 & 14 & .93 & .12 & .04 & .50 & .82 & .88 \\
\hline German self-concept (7) & 41.6 & 14 & .98 & .05 & .03 & .34 & .73 & .83 \\
\hline French self-concept (7) & 64.8 & 14 & .97 & .08 & .02 & .63 & .83 & .86 \\
\hline
\end{tabular}

Note. All $\chi^{2}$ goodness-of-fit tests were statistically significant at $p<.001$; CFI = Comparative Fit Index; RMSEA = Root Mean Square Error of Approximation; SRMR = Standardized Root Mean Square Residual; Min = minimum; Mdn = median; Max = maximum.

whether the single item measures (and short forms) can be used to measure affective motivational constructs other than academic anxieties and academic self concepts.

\subsection{Conclusion}

Short forms of domain general and domain specific academic anxieties and academic self concepts can be recommended as rea sonable alternatives to their corresponding long scales when study designs require brief measures. The results of the present study were also encouraging with regard to the use of single item mea sures. Thus, when a questionnaire becomes too long or when long scales or short forms are not applicable for substantive reasons, single item measures may be considered as the only or in some cases even the best way to obtain valid empirical data on the two core motivational affective student characteristics of aca demic anxiety and academic self concept.

\section{Appendix A}

See Tables A1 A3.

\section{Appendix B. Supplementary material}

Supplementary data associated with this article can be found, in the online version, at http://dx.doi.org/10.1016/j.cedpsych. 2014.04.002.

\section{References}

Ainley, M., \& Patrick, L. (2006). Measuring self-regulated learning processes through tracking patterns of student interaction with achievement activities. Educational Psychology Review, 18(3), 267-286.

Baumeister, R. F., Vohs, K. D., \& Funder, D. C. (2007). Psychology as the science of self-reports and finger movements: Whatever happened to actual behavior? Perspectives in Psychological Science, 2, 396-408.

Bean, A. G., \& Roszkowski, M. J. (1995). The long and short of it. Marketing Research, 7(1), 20-26.

Bentler, P. M. (2009). Alpha, dimension-free, and model-based internal consistency reliability. Psychometrika, 74, 137-143.

Browne, M. W., \& Cudeck, R. (1993). Alternative ways of assessing model fit. In K. Bollen \& J. Long (Eds.), Testing structural equation models (pp. 136-162). Newbury Park, CA: Sage.

Brunner, M., Keller, U., Dierendonck, C., Reichert, M., Ugen, S., Fischbach, A., et al. (2010). The structure of academic self-concepts revisited: The nested Marsh/ Shavelson model. Journal of Educational Psychology, 102(4), 964-981. http:// dx.doi.org/10.1037/a0019644.

Brunner, M., Keller, U., Hornung, C., Reichert, M., \& Martin, R. (2009). The crosscultural generalizability of a new structural model of academic self-concepts. Learning and Individual Differences, 19, 387-403.

Brunner, M., Nagy, G., \& Wilhelm, O. (2012). A tutorial on hierarchically structured constructs. Journal of Personality, 80, 796-846. http://dx.doi.org/10.1111/j.14676494.2011.00749.x.
Byrne, B. M. (1996b). Measuring self-concept across the life span: Issues and instrumentation. Washington, DC: American Psychological Association.

Byrne, B. M. (1996a). Academic self-concept: Its structure, measurement, and relation to academic achievement. In B. A. Bracken (Ed.), Handbook of selfconcept (pp. 287-316). New York, NY: Wiley.

Cheung, M. W.-L. (2009). Constructing approximate confidence intervals for parameters with structural equation models. Structural Equation Modeling, 16, 267-294.

Chiam, H. (1987). Change in self-concept during adolescence. Adolescence, 22, 69-76.

Christophersen, T., \& Konradt, U. (2011). Reliability, validity, and sensitivity of a single-item measure of online store usability. International Journal of HumanComputer Studies, 69(4), 269-280.

Credé, M., Harms, P., Niehorster, S., \& Gaye-Valentine, A. (2012). An evaluation of the consequences of using short measures of the Big Five personality traits. Journal of Personality and Social Psychology, 102(4), 874-888. http://dx.doi.org/ 10.1037/a0027403.

Diener, E. (1984). Subjective well-being. Psychological Bulletin, 95(3), 542-575.

Diener, E. (2000). Subjective well-being: The science of happiness, and a proposal for national index. American Psychologist, 55, 34-43.

Donnellan, M. B., Oswald, F. L., Baird, B. M., \& Lucas, R. E. (2006). The mini-IPIP scales: Tiny-yet-effective measures of the Big Five factors of personality. Psychological Assessment, 18(2), 192.

Eid, M., Lischetzke, T., Nussbeck, F. W., \& Trierweiler, L. I. (2003). Separating trait effects from trait-specific method effects in multitrait-multimethod models: A multiple-indicator CT-C(M-1) model. Psychological Methods, 8, 38-60.

Ganzeboom, H. B. G., de Graaf, P. M., Treiman, D. J., \& de Leeuw, J. (1992). A standard international socio-economic index of occupational status. Social Science Research, 21, 1-56.

Gardner, D. G., Cummings, L. L., Dunham, R. B., \& Pierce, J. L. (1998). Single-item versus multiple-item measurement scales: An empirical comparison. Educational and Psychological Measurement, 58(6), 898-915. http://dx.doi.org/ $10.1177 / 0013164498058006003$.

Girard, T. A., \& Christensen, B. K. (2008). Clarifying problems and offering solutions for correlated error when assessing the validity of selected-subtest short forms. Psychological Assessment, 20(1), 76-80.

Goetz, T. (2004). Emotionales Erleben und selbstreguliertes Lernen bei Schülern im Fach Mathematik [Students' emotions and selfregulated learning in mathematics]. Munich: Utz.

Goetz, T., Bieg, M., Lüdtke, O., Pekrun, R., \& Hall, N. C. (2013). Do girls really experience more anxiety in mathematics? Psychological Science, 24(10), 2079-2087. http://dx.doi.org/10.1177/0956797613486989.

Goetz, T., Cronjaeger, H., Frenzel, A. C., Lüdtke, O., \& Hall, N. C. (2010). Academic selfconcept and emotion relations: Domain specificity and age effects. Contemporary Educational Psychology, 35(1), 44-58.

Goetz, T., Frenzel, C. A., Hall, N. C., \& Pekrun, R. (2008). Antecedents of academic emotions: Testing the internal/external frame of reference model for academic enjoyment. Contemporary Educational Psychology, 33, 9-33.

Goetz, T., Frenzel, A. C., Pekrun, R, Hall, N. C. \& Lüdtke, O. (2007). Between-and within-domain relations of students' academic emotions. Journal of Educational Psychology, 99(4), 715.

Goetz, T., Frenzel, A. C., Stoeger, H., \& Hall, N. C. (2010). Antecedents of everyday positive emotions: An experience sampling analysis. Motivation and Emotion, 34(1), 49-62. http://dx.doi.org/10.1007/s11031-009-9152-2.

Goetz, T., Preckel, F., Pekrun, R., \& Hall, N. (2007). Emotional experiences during test taking: Does cognitive ability make a difference? Learning and Individual Differences, 17, 3-16. http://dx.doi.org/10.1016/j.lindif.2006.12.002.

Goetz, T., Preckel, F., Zeidner, M., \& Schleyer, E. J. (2008). Anxiety of big fish swimming in big ponds: A multilevel analysis of test anxiety and achievement in special gifted classes. Anxiety, Stress, and Coping, 21, 185-198.

Gosling, S. D., Rentfrow, P. J., \& Swann, W. B. (2003). A very brief measure of the Big-Five personality domains. Journal of Research in Personality, 37(6), 504-528. 
Gottfried, A. E. (1982). Relationships between academic intrinsic motivation and anxiety in children and young adolescents. Journal of School Psychology, 20, 205-315.

Hansford, B. C., \& Hattie, J. A. (1982). The relationship between self and achievement/performance measures. Review of Educational Research, 52, $123-142$.

Hattie, J. A. (1992). Self-concept. Hillsdale, NJ: Erlbaum.

Haynes, S. N., Richard, D. C. S., \& Kubany, E. S. (1995). Content validity in psychological assessment: A functional approach to concepts and methods. Psychological Assessment, 7, 238-247.

Helmke, A., \& van Aken, M. A. G. (1995). The causal ordering of academic achievement and self-concept of ability during elementary school: A longitudinal study. Journal of Educational Psychology, 87, 624-637.

Hembree, R. (1988). Correlates, causes, effects, and treatment of test anxiety. Review of Educational Research, 58, 47-77.

Hembree, R. (1990). The nature, effects, and relief of mathematics anxiety. Journal for Research in Mathematics Education, 21(1), 33-46. http://dx.doi.org/10.2307/ 749455.

Hergovich, A., Sirsch, U., \& Felinger, M. (2004). Gender differences in the selfconcept of preadolescent children. School Psychology International, 25, 207-222.

Hinkin, T. R. (1998). A brief tutorial on the development of measures for use in survey questionnaires. Organizational Research Methods, 1(1), 104-121.

Hoeppner, B. B., Kelly, J. F., Urbanoski, K. A., \& Slaymaker, V. (2011). Comparative utility of a single-item versus multiple-item measure of self-efficacy in predicting relapse among young adults. Journal of Substance Abuse Treatment, 41(3), 305-312.

Hu, L.-T., \& Bentler, P. M. (1998). Fit indices in covariance structure modeling: Sensitivity to underparameterized model misspecification. Psychological Methods, 3, 424-453.

Huebner, E. S. (1994). Conjoint analysis of the students' life satisfaction scale and the piers-harris self-concept scale. Psychology in the Schools, 31(4), 273-277.

Iacobucci, D. (2010). Structural equations modeling: Fit Indices, sample size, and advanced topics. Journal of Consumer Psychology, 20, 90-98.

Jackson, L. A., Hodge, C. N., \& Ingram, J. M. (1994). Gender and self-concept: Are examination of stereotypic differences and the role of gender attitudes. Sex Roles, 30, 615-630.

Jordan, J. S., \& Turner, B. A. (2008). The feasibility of single-item measures for organizational justice. Measurement in Physical Education and Exercise Science, 12(4), 237-257. http://dx.doi.org/10.1080/10913670802349790.

Kline, R. B. (2010). Principles and practice of structural equation modeling (3rd ed.). New York: Guilford Press.

Konstabel, K., Lönnqvist, J.-E., Walkowitz, G., Konstabel, K., \& Verkasalo, M. (2012) The "Short Five" (S5): Measuring personality traits using comprehensive single items. European Journal of Personality, 26(1), 13-29. http://dx.doi.org/10.1002/ per.813.

Lau, S., Siu, C. K. K., \& Chik, M. P. Y. (1998). The self-concept development of Chinese primary schoolchildren: A longitudinal study. Childhood: A Global Journal of Child Research, 5, 69-97.

Lee, J. (2009). Universals and specifics of math self-concept, math self-efficacy, and math anxiety across 41 PISA 2003 participating countries. Learning and Individual Differences, 19(3), 355-365.

Levy, P. (1967). The correction for spurious correlation in the evaluation of shortform tests. Journal of Clinical Psychology, 23(1), 84-86.

Levy, P. (1968). Short-form tests: A methodological review. Psychological Bulletin 69(6), 410.

Liebert, R. M., \& Morris, L. W. (1967). Cognitive and emotional components of test anxiety: A distinction and some initial data. Psychological Reports, 20, 975-978.

Linnenbrink, E., \& Pintrich, P. R. (2000). Multiple pathways to learning and achievement: The role of goal orientation in fostering adaptive motivation. Affect and cognition. In C. Sansone \& J. Harackiewicz (Eds.), Intrinsic and extrinsic motivation: The search for optimal motivation and performance (pp. 195-227). San Diego, CA: Academic Press.

Little, T. D., Preacher, K. J., Selig, J. P., \& Card, N. A. (2007). New developments in latent variable panel analyses of longitudinal data. International Journal of Behavioral Development, 31(4), 357-365. http://dx.doi.org/10.1177/ 0165025407077757.

Loo, R. (2002). A caveat on using single-item versus multiple-item scales. Journa of Managerial Psychology, 17(1), 68-75. http://dx.doi.org/10.1108/ 02683940210415933

Lord, F. I., \& Novick, M. R. (1968). Statistical theories of mental test scores. MA Addison-Wesley.

Lucas, R. E., \& Donnellan, B. M. (2012). Estimating the reliability of single-item life satisfaction measures: Results from four national panel studies. Social Indicators Research, 105(3), 323-331. http://dx.doi.org/10.1007/s11205-011-9783-z.

Ma, X. (1999). A meta-analysis of the relationship between anxiety toward mathematics and achievement in mathematics. Journal for Research in Mathematics Education, 28(1), 26-47.

Ma, X., \& Kishor, N. (1997). Assessing the relationship between attitude toward mathematics and achievement in mathematics: A meta-analysis. Journal for Research in Mathematics Education, 28(1), 27-47.

Mandler, G., \& Sarason, S. B. (1952). A study of anxiety and learning. Journal of Abnormal and Social Psychology, 47, 166-173.

Marsh, H. W. (1986). Global self-esteem: Its relation to specific facets of selfconcept and their importance. Journal of Personality and Social Psychology, 51 $1224-1236$
Marsh, H. W. (1987). The big-fish-little-pond effect on academic self-concept. Journal of Educational Psychology, 79, 280-295.

Marsh, H. W. (1988). Self Description Questionnaire: A theoretical and empirical basis for the measurement of multiple dimensions of preadolescent self-concept: A tes manual and a research monograph. San Amonio, TX: Psychological Corporation.

Marsh, H. W. (1989). Age and sex effects in multiple dimensions of self-concept: Preadolescence to early adulthood. Journal of Educational Psychology, 81, 417-430.

Marsh, H. W. (1990a). The structure of academic self-concept: The Marsh/Shavelson model. Journal of Educational Psychology, 82, 623-636.

Marsh, H. W. (1990b). Self-Description Questionnaire (SDO) II: A theoretical and empirical basis for the measurement of multiple dimensions of adolescent selfconcept: An interim test manual and a research monograph. Macarthur, New South Wales, Australia: University of Western Sydney.

Marsh, H. W., Abduljabbar, A. S., Abu-Hilal, M. M., Morin, A. J. S., Abdelfattah, F. Leung, K. C., et al. (2013). Factorial, convergent, and discriminant validity of Timss math and science motivation measures: A comparison of Arab and AngloSaxon countries. Journal of Educational Psychology, 105(1), 108-128.

Marsh, H. W., Barnes, J., \& Hocevar, D. (1985). Self-other agreement on multidimensional self-concept ratings: Factor analysis and multitraitmultimethod analysis. Journal of Personality and Social Psychology, 49(5), 1360.

Marsh, H. W., \& Craven, R. (1997). Academic self-concept: Beyond the dustbowl. In G. Phye (Ed.), Handbook of classroom assessment: Learning, achievement, and adjustment (pp. 131-198). Orlando, FL: Academic Press.

Marsh, H. W., Ellis, L. A., Parada, R. H., Richards, G., \& Heubeck, B. G. (2005). A short version of the Self Description Questionnaire II: Operationalizing criteria for short-form evaluation with new applications of confirmatory factor analyses. Psychological Assessment, 17(1), 81.

Marsh, H. W., Hau, K. T., Artelt, C., Baumert, J., \& Peschar, J. L. (2006). OECD's brief self-report measure of educational psychology's most useful affective constructs: Cross-cultural, psychometric comparisons across 25 countries. International Journal of Testing, 6(4), 311-360.

Marsh, H. W., Kong, C. K., \& Hau, K. (2000). Longitudinal multilevel models of the Big-Fish-Little-Pond Effect on academic self-concept: Counterbalancing contrast and reflected glory effects in Hong Kong schools. Journal of Personality and Social Psychology, 78, 337-349.

Marsh, H. W., \& O'Mara, A. J. (2008). Reciprocal effects between academic selfconcept, self-esteem, achievement and attainment over seven adolescent-adult years: Unidimensional and multidimensional perspectives of self-concept. Personality and Social Psychology Bulletin, 34, 542-552.

Marsh, H. W., \& O'Neill, R. (1984). Self Description Questionnaire III (SDQ III): The construct validity of multidimensional self-concept ratings by late adolescents. Journal of Educational Measurement, 21, 153-174.

Marsh, H. W. \& Parker, J. W. (1984). Determinants of student self-concept: Is it better to be a relatively large fish in a small pond even if you don't learn to swim as well? Journal of Personality and Social Psychology, 47, 213-231.

Marsh, H. W., Smith, I. D., \& Barnes, J. (1985). Multidimensional self-concepts: Relations with sex and academic achievement. Journal of Educational Psychology, $77,581-596$.

Marsh, H. W., Trautwein, U., Lüdtke, O., Koller, O., \& Baumert, J. (2005). Academic selfconcept, interest, grades and standardized test scores: Reciprocal effects models of causal ordering. Child Development, 76(2), 397-416.

Marsh, H. W., \& Yeung, A. S. (1997). Coursework selection: Relations to academic self-concept and achievement. American Educational Research Journal, 34 691-720.

Marsh, H. W., \& Yeung, A. S. (1998). Longitudinal structural equation models of academic self-concept and achievement: Gender differences in the development of math and English constructs. American Educational Research Journal, 35, 705-738.

Martin, R., \& Brunner, M. (Eds.). (2012). Nationaler Bericht: Épreuves Standardisées ÉpStan) - Schuljahr 2011/2012. Luxemburg: Universität Luxemburg, Forschungseinheit EMACS.

McCormack, H. M., Horne, D. d. L., \& Sheather, S. (1988). Clinical applications of visual analogue scales: A critical review. Psychological Medicine 18,1007-1019.

McCrae, R. R., Kurtz, J. E., Yamagata, S., \& Terracciano, A. (2011). Internal consistency, retest reliability, and their implications for personality scale validity. Personality and Social Psychology Review, 15, 28-50.

McDonald, R. P. (1999). Test theory: A unified treatment. Mahwah, NJ: Lawrence Erlbaum Associates.

McKnight, P. E., McKnight, K. M., Sidani, S., \& Figueredo, A. J. (2007). Missing data: A gentle introduction. Guilford Press.

Möller, J., Pohlmann, B., Köller, O., \& Marsh, H. W. (2009). A meta-analytic path analysis of the internal/external frame of reference model of academic achievement and academic self-concept. Review of Educational Research, 79, 1129-1167.

Moore, K. A., Halle, T. G., Vandivere, S., \& Mariner, C. L. (2002). Scaling back survey scales. How short is too short? Sociological Methods E Research, 30(4), $530-567$.

Muthén, L. K., \& Muthén, B. O. (1998-2010). Mplus user's guide (6th ed.). Los Angeles, CA: Muthén \& Muthén.

Nagy, M. S. (2002). Using a single-item approach to measure facet job satisfaction. Journal of Occupational and Organizational Psychology, 75(1), 77-86. http:// dx.doi.org/10.1348/096317902167658.

Nett, U. E., Goetz, T., \& Hall, N. C. (2011). Coping with boredom in school: An experience sampling perspective. Contemporary Educational Psychology, 36(1), 49-59. 
Nevo, B. (1985). Face validity revisited. Journal of Educational Measurement, 22, 287-293.

Niepel, C., Brunner, M., \& Preckel, F. (2014). The longitudinal interplay of students' academic self-concepts and achievements within and across domains: Replicating and extending the reciprocal internal/external frame of reference model. Journal of Educational Psychology. http://dx.doi.org/10.1037/a0036307.

Nunally, J. C., Psychometric theory, 2nd ed., 1978, New York.

Pekrun, R., Goetz, T., Frenzel, A. C., Barchfeld, P., \& Perry, R. P. (2011). Measuring emotions in students' learning and performance: The achievement emotions questionnaire (AEQ). Contemporary Educational Psychology, 36(1), 36-48.

Pfeiffer, N., Hagemann, D., \& Backenstrass, M. (2011). A new method for estimating the variance overlap between the short and the long form of a psychological test. Educational and Psychological Measurement, 71(2), 380-388. http:// dx.doi.org/10.1177/0013164410386782.

Preckel, F., \& Brüll, M. (2008). Grouping the gifted and talented: Are gifted girls most likely to suffer the consequences? Journal for the Education of the Gifted, 32, 54-85. http://dx.doi.org/10.4219/jeg-2008-822.

Preckel, F., Goetz, T., Pekrun, R., \& Kleine, M. (2008). Gender differences in gifted and average-ability students: Comparing girls' and boys' achievement, self-concept, interest, and motivation in mathematics. Gifted Child Quarterly, 52, 146-159. http://dx.doi.org/10.1177/0016986208315834.

Rammstedt, B., \& John, O. P. (2007). Measuring personality in one minute or less: A 10 -item short version of the Big Five Inventory in English and German. Journal of Research in Personality, 41(1), 203-212.

Reise, S. P., Moore, T. M., \& Haviland, M. G. (2010). Bifactor models and rotations: Exploring the extent to which multidimensional data yield univocal scale scores. Journal of Personality Assessment, 92, 544-559.

Reise, S. P., Morizot, J., \& Hays, R. D. (2007). The role of the bifactor model in resolving dimensionality issues in health outcomes measures. Quality of Life Research, 16, 19-31.

Rhemtulla, M., Brosseau-Liard, P., \& Savalei, V. (2012). When can categorical variables be treated as continuous? A comparison of robust continuous and categorical SEM estimation methods under sub-optimal conditions. Psychological Methods, 17, 354-373.

Robins, R. W. Hendin, H. M. \& Trzesniewski, K. H. (2001). Measuring global self-esteem: Construct validation of a single-item measure and the Rosenberg Self-Esteem Scale. Personality and Social Psychology Bulletin, $27(2), 151-161$.

Scarpello, V., \& Campbell, J. P. (1983). Job satisfaction: Are all the parts there? Personnel Psychology, 36, 577-600.

Schaeffer, N. C., \& Presser, S. (2003). The science of asking questions. Annual Review of Sociology, 29, 65-88.

Scherer, K. R. (1984). On the nature and function of emotion: A component process approach. In K. R. Scherer \& P. Ekman (Eds.), Approaches to emotion (pp. 293-317). Hillsdale, NJ: Erlbaum.

Seipp, B. (1991). Anxiety and academic performance: A meta-analysis of findings. Anxiety Research. An International Journal, 4, 27-41.

Skaalvik, E. M., \& Rankin, R. J. (1990). Math, verbal, and general academic selfconcept: The internal/external frame of reference model and gender differences in selfconcept structure. Journal of Educational Psychology, 82, 546-554.
Smith, G. T., McCarthy, D. M., \& Anderson, K. G. (2000). On the sins of short-form development. Psychological Assessment, 12(1), 102.

Spielberger, C. D. (1980). Test anxiety inventory: Preliminary professional manual. Palo Alto, CA: Consulting Psychologists Press.

Stanton, J. M., Sinar, E. F., Balzer, W. K., \& Smith, P. C. (2002). Issues and strategies for reducing the length of self-report scales. Personnel Psychology, 55(1), 167-194.

Stipek, D. J., \& Mason, T. C. (1987). Attributions, emotions, and behavior in the elementary school classroom. Journal of Classroom Interaction, 22, 1-5.

Swann, W. B., Jr., Chang-Schneider, C., \& McClarty, K. (2007). Do our self-views matter? Self-concept and self-esteem in everyday life. American Psychologist, 62, 84-94.

Trautwein, U., Lüdtke, O., Marsh, H. W., Köller, O., \& Baumert, J. (2006). Tracking, grading, and student motivation: Using group composition and status to predict self-concept and interest in ninth-grade mathematics. Journal of Educational Psychology, 98(4), 788.

Trautwein, U., Lüdtke, O., Schnyder, I., \& Niggli, A. (2006). Predicting homework effort: Support for a domain-specific, multilevel homework model. Journal of Educational Psychology, 98, 438-456.

Valentine, J. C., DuBois, D. L., \& Cooper, H. (2004). The relation between self-beliefs and academic achievement: A meta-analytic review. Educational Psychologist, 39(2), 111-133. http://dx.doi.org/10.1207/s15326985ep3902_3.

Wanous, J. P., Reichers, A. E., \& Hudy, M. J. (1997). Overall job satisfaction: How good are single-item measures? Journal of Applied Psychology, 82(2), 247.

Wirth, R. J., \& Edwards, M. C. (2007). Item factor analysis: Current approaches and future directions. Psychological Methods, 12, 58-79.

Wittmann, W. W. (1988). Multivariate reliability theory: Principles of symmetry and successful validation strategies. In J. R. Nesselroade \& R. B. Cattell (Eds.), Handbook of multivariate experimental psychology (2nd ed., pp. 505-560). New York: Plenum.

Wu, M. L., Adams, R. J., Wilson, M. R., \& Haldane, S. A. (2007). ACER ConQuest Version 2: Generalised item response modelling software. Camberwell: Australian Council for Educational Research.

Yang, Y., \& Green, S. B. (2010). A note on structural equation modeling estimates of reliability. Structural Equation Modeling, 17, 66-81.

Yang, Y., \& Green, S. B. (2011). Coefficient alpha: A reliability coefficient for the 21st Century? Journal of Psychoeducational Assessment, 29(4), 377-392. http:// dx.doi.org/10.1177/0734282911406668.

Zeidner, M. (1998). Test anxiety: The state of the art. New York: Plenum Press.

Zeidner, M., Nevo, B., \& Lipschitz, H. (1988). The Hebrew version of the test anxiety inventory. Haifa, Israel: Univ. of Haifa.

Zeidner, M. (2007). Test anxiety: Conceptions, findings, conclusions. In P. Schutz \& R. Pekrun (Eds.), Emotion in education (pp. 165-184). San Diego, CA: Academic Press.

Zinbarg, R. E., Revelle, W., Yovel, I., \& Li, W. (2005). Cronbach's alpha, Revelle's beta, and McDonald's omega h: Their relations with each other and two alternative conceptualizations of reliability. Psychometrika, 70, 123-133.

Zinbarg, R. E., Yovel, I., Revelle, W., \& McDonald, R. P. (2006). Estimating generalizability to a latent variable common to all of a scale's indicators: A comparison of estimators for $\omega \mathrm{h}$. Applied Psychological Measurement, 30, 121-144. 